\title{
Is Business Cycle Asymmetry Intrinsic in Industrialized Economies?
}

\author{
James Morley \\ University of Sydney \\ Sydney NSW 2006 \\ Australia \\ Email: james.morley@sydney.edu.au
}

\author{
Irina B. Panovska ${ }^{1}$ \\ Lehigh University \\ Bethlehem, PA 18015 \\ USA \\ Email: irp213@lehigh.edu
}

This Draft: June $7^{\text {th }} 2018$

\begin{abstract}
We consider a model-averaged forecast-based estimate of the output gap to measure economic slack in ten industrialized economies. Our measure takes changes in the long-run growth rate into account and, by addressing model uncertainty using equal weights on different forecastbased estimates, is robust to different assumptions about the underlying structure of the economy. For all ten countries in the sample, we find that the estimated output gap has much larger negative movements during recessions than positive movements in expansions, suggesting business cycle asymmetry is an intrinsic characteristic of industrialized economies. Furthermore, the estimated output gap is always strongly negatively correlated with future output growth and unemployment and positively correlated with capacity utilization. It also implies a convex Phillips Curve in many cases. The model-averaged output gap is reliable in real time in the sense of being subject to relatively small revisions.
\end{abstract}

JEL Codes: E32; E37

Keywords: output gap; model averaging; Markov switching; business cycle asymmetry; convex Phillips Curve

\footnotetext{
${ }^{1}$ Corresponding author. An earlier version of this study that focused on Asia-Pacific economies circulated under the title of "Measuring Economic Slack: A Forecast-Based Approach with Applications to Economies in Asia and the Pacific". We thank the associate editor and two anonymous referees for helpful comments and suggestions. We also thank Stephane Dees, Jun Il Kim, Aaron Mehrotra, Tim Robinson, James Yetman, and Alex Nikolsko-Rzhevskyy, as well as conference and seminar participants at the 2017 Symposium of the Society for Nonlinear Dynamics and Econometrics, the Bureau of Economic Analysis, Lafayette College, the University of Wisconsin Whitewater, People's Bank of China-BIS Conference on "Globalisation and Inflation Dynamics in Asia and the Pacific", the "Continuing Education in Macroeconometrics workshop at the University of New South Wales, the Sydney Macroeconomics Readings Group, the European Central Bank, and the University of Technology Sydney for helpful questions and comments. The usual disclaimers apply.
} 


\section{Introduction}

There is relatively little consensus in macroeconomics about how best to measure economic slack. Even settling on the output gap (i.e., the difference between actual and potential log real GDP for an economy) as the preferred measure, there remains the challenge of defining and calculating "potential". Common decomposition methods that assume a linear structure for the economy, such as the widely-used Hodrick-Prescott (1997) (HP) filter, an unobserved components (UC) model with uncorrelated components (Clark, 1987), and a UC model with correlated components (Morley, Nelson, and Zivot, 2003), can lead to very different estimates of the output gap, as shown by, for example, Morley, Nelson, and Zivot (2003) or Perron and Wada (2016). A recent study by Hamilton (2018) also highlights several drawbacks of the HP filter, in particular the fact that it can generate cycles with spurious dynamics. Furthermore, there is a vast literature that documents a possible nonlinear structure for the economy (see, for example, Hamilton, 1989, Kim, 1994, Kim and Nelson, 1999, Kim, Morley and Piger, 2005, and Sinclair, 2010). However, as we show in our analysis, formal hypothesis tests provide only mixed evidence that nonlinear models of aggregate output are preferable to linear models. Given a lack of strong evidence for a single empirical specification of the economy that outperforms all other models, we propose a model-averaged forecast-based estimate of the output gap as the appropriate measure of economic slack.

In terms of the forecast-based approach adopted in this paper, it is based on the idea that the presence or absence of economic slack directly implies whether an economy can or cannot grow faster than its long-run average growth rate without necessarily leading to subpar growth in the future. In particular, if the optimal forecast of future output growth is above average, then output will be estimated to be below potential and vice versa. This approach implicitly defines "potential" as the stochastic trend of log real GDP and has its origins in the influential study by Beveridge and Nelson (1981, BN hereafter).

Given a forecast-based approach to estimating the output gap, it is necessary to confront the question of how best to construct a reasonable forecast of future output growth. BN consider low-order ARMA models, which result in small output gaps, often with counterintuitive sign (e.g., the estimated gap is often positive during recessions). Motivated by the different results and mixed evidence for different models discussed above, as well as the forecasting literature 
and recent studies on estimating the output gap by Garratt, Mitchell, and Vahey (2014) and Morley and Piger (2012), we consider model-averaged forecasts instead of relying on one particular time series model or class of models. Importantly, we follow Morley and Piger (2012) by including nonlinear time series models in the model set under consideration. Notably, this approach will not necessarily result in output gap estimates of counterintuitive sign as long as the model-averaged forecasts imply negative serial correlation in economic growth at longer horizons.

For our analysis, we measure economic slack in ten industrialized economies, taking structural breaks in long-run growth into account. ${ }^{2}$ Our measure of economic slack is a modified version of the model-averaged estimate of the output gap used by Morley and Piger (2012) for US real GDP. In particular, while we consider the same broad set of both linear and nonlinear models from Morley and Piger (2012) with the addition of Hamilton's (2018) model, we place equal weights on all models considered and we incorporate prior beliefs from previous analysis when conducting Bayesian estimation of model parameters. Given the diverse set of linear and nonlinear models, our simplified approach of using equal weights produces similar results to estimating optimal weights for the United States. However, equal weights and Bayesian estimation are much easier to implement for a broad range of economies than the more complicated approach to model averaging and maximum likelihood estimation of the nonlinear models taken in Morley and Piger (2012). ${ }^{3}$

We have three main goals in this paper. First, we seek to demonstrate that a simpler version of the methods in Morley and Piger (2012) can replicate the results for US data, but is more broadly applicable to data for other countries and appears to work better than estimating model weights in many cases, especially for countries that have more limited data availability and shorter data samples. Second, we check whether the output gaps we obtain for a set of ten industrialized economies exhibit the expected patterns in terms of correlations with future output growth, inflation, and narrower measures of slack, while comparing these patterns with those for output

\footnotetext{
${ }^{2}$ We are motivated to consider industrialized economies to determine whether there are any intrinsic characteristics for their output gaps, much like Levin and Piger (2006) investigated intrinsic characteristics for inflation rates in industrialized economies.

${ }^{3}$ GAUSS code for calculation of the model-averaged estimate of the output gap is available at https://sites.google.com/site/jamescmorley/research/code.
} 
gaps obtained from other methods. Third, we consider whether the asymmetry in terms of much larger negative movements during recessions than positive movements in expansions found for the U.S. data is an intrinsic characteristic of business cycles for other industrialized economies.

Our model-averaged estimate of the output gap produces a consistent picture of the business cycle across all ten industrialized economies under consideration. In particular, despite the fact that tests for nonlinearity give mixed statistical evidence in favor of nonlinearity, there is clear empirical support for the idea that output gaps are subject to much larger negative movements during recessions than positive movements in expansions for all ten countries in the sample. This is an important finding because it suggests this form of business cycle asymmetry is not just a characteristic of the U.S. economy, but is intrinsic in industrialized economies more generally. We perform a simulation to demonstrate that this finding of asymmetry is not driven by the fact that we include nonlinear models in our set of models. In the case where the true data-generating process (DGP) is linear, the estimated output gap using our approach is symmetric. Furthermore, our estimated output gaps have strong negative forecasting relationships with future output growth in all cases and are closely related to narrower measures of slack given by the unemployment rate and capacity utilization. These results support the accuracy of the modelaveraged estimates in comparison with other estimates of the output gap. Results for a Phillips curve relationship with inflation are more mixed, but there is evidence in favor of a convex relationship for a number of economies, arguing against the imposition of a linear relationship when estimating output gaps, such as is done by Kuttner (1994) and in many other studies. Finally, using real-time data for the United States, we show that the model-averaged output gap also produces reliable estimates in real time in the sense of being subject to relatively small revisions.

The rest of this paper is organized as follows. Section 2 discusses the data, including the possible presence of structural breaks in long-run growth for each economy. Section 3 motivates the model-averaging approach by demonstrating the sensitivity of the estimate of the output gap to the time series model under consideration. Section 4 presents the empirical models and methods used in the analysis. Section 5 reports the results first for the benchmark U.S. case and then for a group of other industrialized economies. Section 6 discusses the performance of the model averaged output gap in real time. Section 7 concludes. 


\section{Data}

We consider macroeconomic data for the United States (US) and nine other industrialized economies: Australia (AU), Canada (CA), France (FRA), Germany (DEU), Italy (IT), Japan (JP), Korea (KR), New Zealand (NZ), and the United Kingdom (UK). Our sample was selected with the intention of examining a representative set of industrialized economies. In particular, we include the large to medium-sized G7 economies, an additional medium-sized economy with many similar characteristics to the G7 economies (i.e., Australia), a somewhat smaller economy that also has many similar characteristics to the G7 economies (i.e., New Zealand), and an emergent medium-sized industrialized economy that has undergone several structural changes, but has reliable data (i.e., Korea). Data series for real GDP, the price level, the unemployment rate, and capacity utilization were sourced from OECD databases and from relevant national data sources. See Table A.1 in the appendix for full details.

For quarterly real GDP, we use the seasonally-adjusted series and construct quarterly growth rates by taking first differences of 100 times the natural logs of the levels. The sample periods for quarterly growth rates are listed in Table 1 and real GDP (100 time the natural log) for all countries is plotted in Figure 1.

For the price level, we use the core PCE deflator for the United States, core CPI for Canada, Germany, France, and the United Kingdom, and headline CPI for the remaining economies. These choices were determined by a general preference for core measures, but only when they are available for a relatively long sample period in comparison to real GDP. We calculate inflation as the year-on-year percentage change in the price level and then construct 4-quarterahead changes in inflation. The relevant sample periods based on common availability of both real GDP, price level data, the unemployment rate data, and capacity utilization are listed in Table 3 in the next section.

In addition to sample periods for the real GDP growth rate data, Table 1 reports estimated structural break dates for long-run growth rates-i.e., expected growth in the absence of shocks. Perron and Wada (2009) argue that it is crucial to account for a structural break in the long-run growth rate of US real GDP when measuring economic slack for the US economy using unobserved components models. They impose a break date of 1973Q1 based on the notion of a 
productivity growth slowdown at that time. Similarly, Perron and Wada (2016) show that that the popular Hodrick-Prescott (HP) filter is sensitive to the treatment of structural breaks and to outliers. In particular, they show that that accounting for structural breaks can lead to very different inference about the output cycle in G7 economies. Thus, we allow for structural breaks in long-run growth rates. The full structural break test results are presented in Table A.2 in the appendix.

When applying Bai and Perron's $(1998,2003)$ sequential testing procedure for structural breaks in the mean growth rate of US real GDP, we do not detect any break in the early 1970s. Instead, we find the estimated break date is 2000Q3. This break is significant at the 1\% level and corresponds to a reduction in the mean growth rate. There is only weak evidence in favor of a second structural break in 1973Q1 ( $p$-value is 0.13). However, following much of the literature, including Perron and Wada (2009, 2016), and acknowledging the possibility of weak power in finite samples, we also allow for a second structural break in 1973Q1. ${ }^{4}$ We discuss the consequences of imposing different break dates and demonstrate that our results are robust to using a more agnostic approach based on dynamic demeaning rather than imposing structural breaks in the supplemental online appendix.

It also turns out also to be important to account for structural breaks in long-run growth for the other economies as well. With the exception of Australia and New Zealand, we find structural breaks for all other economies. The estimated break dates and the corresponding sequence of mean growth regimes are reported in Table 1. We find evidence of one structural break for Canada, France, Italy, Korea, and the UK and evidence in favor of two structural breaks for

\footnotetext{
${ }^{4}$ Following much of the applied literature, we consider trimming of $15 \%$ of the sample from its end points and between breaks for admissible break dates. But even when using 5\% trimming, we find no evidence of an additional structural break for the US in the mid-1970s at the $10 \%$ level. As discussed in more detail in the supplemental online appendix, not allowing for a second break in 1973 leads to estimates of output slack that are very strongly at odds with measures of slack from the previous literature and with more narrowly defined measures of slack, such as the unemployment rate. Given the broad evidence in favor of a break in 1973 from the previous literature, we impose a second break in 1973Q1. In general, we find that it is more problematic to underestimate than to overestimate the number of structural breaks when calculating forecast-based output gaps. Specifically, forecast-based output gaps can display permanent movements that proxy for large structural breaks in growth rates when these are not directly accounted for, while accounting for smaller or possibly misspecified structural breaks tends to have little impact on forecast-based output gaps. Furthermore, as shown in the supplemental online appendix, our results are robust when we use a more agnostic approach where the growth rates are calculated using rolling window averages rather than imposed break dates.
} 
Germany and Japan. ${ }^{5}$ To account for structural breaks in subsequent analysis, the output growth series are mean-adjusted based on the estimated average growth rate in each regime until there is no remaining evidence of additional breaks. ${ }^{6}$

\section{Motivation}

We motivate the model-averaging approach to measuring economic slack described in the next section by first considering forecast-based estimates of the output gap based on two commonly used models and a very recent approach proposed by Hamilton (2018). In particular, we consider an AR(1) model, Harvey and Jaeger's (1993) unobserved components (UC) model that corresponds to the commonly used Hodrick-Prescott (HP) filter with a smoothing parameter of 1,600 (denoted UC-HP hereafter), and Hamilton's (2018) regression based filter. The AR(1) model is estimated for quarterly real GDP growth and the output gap is estimated using the BN decomposition for an AR(1) model. The UC-HP model is estimated for 100 times the natural logs of quarterly real GDP and the output gap is estimated using the Kalman filter, while Hamilton's (2018) model is estimated using a linear regression for 100 times the natural log of quarterly real GDP. Although it is specified in terms of log levels, the UC-HP model provides an

\footnotetext{
${ }^{5}$ The regression model for testing structural breaks includes only a constant. The evidence for structural breaks is generally weaker when allowing for serial correlation. In addition, the $p$-value for the test statistics for the second structural break in Germany in 1991Q2 was only significant at the 0.11 level. Similarly, the test statistics for the structural break in the UK in 1973Q1 was only significant at the 0.15 level. The OEDC series for German real GDP is adjusted for the reunification level shift, but there is still evidence, albeit somewhat weak, in favor of a slope shift. However, previous studies for Germany that use a different set of empirical models (see, inter alia, Klinger and Weber, 2016, and Perron and Wada, 2016) find evidence of a break in the early 1990s following the reunification. In addition, when using year-on-year growth rates, we find stronger evidence in favor of a structural break in the UK and of second structural break in Germany. For the UK, when the 1973Q2 break is not taken into account, almost all measures of slack considered here imply that the UK output gap was below trend from 1973Q1 throughout 2016Q1. We therefore impose a structural break in the UK in 1973Q1 and a second structural break in 1991Q2 for Germany. All other breaks reported in Table 1 were significant at the 10\% level. Allowing for additional structural breaks led to model-averaged estimates of the output gap that are very similar to those reported in the paper.

${ }^{6}$ Of course, in this paper the timing of the structural breaks is determined ex-post. If a structural break occurred towards the end of the sample, and one was concerned with obtaining forecasts for future values of the output gaps estimates, a structural break at the end of the sample would make real time-forecasts imprecise and potentially incorrect. However, this is not something that is unique to our approach. All common estimates of the output gap would be affected by a structural break towards the end of the sample (see, for example, De Jong and Sakarya, 2016). Compared to linear models, including models where the output trend is specified as a random walk partially mitigates this problem because the breaks in trend could be proxied as large negative shocks to the trend. Given our key question of whether the business cycles exhibit asymmetric behavior, we believe the best approach to fully evaluate the asymmetric behavior is based on the full information set, and therefore our benchmark specification is one that uses the revised data with imposed breaks. However, as shown in section 6 and in the supplemental online appendix, our estimates are robust to using a more agnostic approach that uses rolling window averages for the average growth rates, and the model averaged output gap estimates are reliable when using real time data.
} 
implicit forecast of future output growth, with the Kalman filter calculating the long-horizon conditional forecast of future output at each point of time.

Figure 2 plots the estimated output gaps based on the AR(1), the UC-HP, and the Hamilton models for real GDP. The top panel presents the results for US real GDP. As discussed in Morley and Piger (2012) for US data, the AR(1) and UC-HP estimates are very different from each other, with the output gap based on the AR(1) model being of small amplitude and positive during NBER-dated recessions, while the output gap based on the UC-HP being of much larger amplitude and negative during NBER-dated recessions. At first sight, it might seem obvious that the UC-HP output gap would be preferable, especially given its more intuitive relationship with recessions and ease of implementation. However, multiple studies (for example, Cogley and Nason, 1995, De Jong and Sakarya, 2016, Perron and Wada, 2016, and Hamilton, 2018) find that the Hodrick-Prescott filter can create large spurious cycles when no actual cycle is present in the underlying data-generating process. Hamilton (2018) proposes an alternative regression-based approach that entails a regression of the variable at date $t+h$ (where $h=8$ for quarterly data) on the four most recent values as of date $t$ as a robust approach to detrending that achieves the objectives sought by the HP filter without its drawbacks. However, the AR(1) model fits the data much better than the UC-HP and the Hamilton regression gap model by any standard metric used for model comparison, including AIC and SIC. ${ }^{7,8}$

\footnotetext{
${ }^{7}$ We follow the approach in Morley and Piger (2012) to ensure the adjusted sample periods are equivalent for all models under consideration. For the linear and nonlinear AR models discussed below, this involves backcasting sufficient observations based on the long-run growth rate to condition on in estimation. For the UC models discussed below, it involves placing a highly diffuse prior on the initial level of the stochastic trend and evaluating the likelihood for the same observations as for the models of growth rates. In the case of the US when comparing the models, for example, the AIC for the AR(1) model is -357.207 and the AIC for the UC-HP model is -599.478, where the AIC is rescaled as in Davidson and MacKinnon (2004) such that larger values are preferred. Similarly, the HPD log-likelihoods for the AR(1) model is -414.01, whereas the HPD log likelihood for the UC-HP model is -679.67.

${ }^{8}$ The Hamilton model is not directly comparable to the AR(1) models as the left-hand-side variable is the level of output rather than the growth rate. However, if the true model is an $\operatorname{AR}(1)$ process, $y_{t}-y_{t-1}=c+$ $\phi\left(y_{t-1}-y_{t-2}\right)+\epsilon_{t}$ which implies that $y_{t}=\mu+(1+\phi) y_{t-1}-\phi y_{t-2}+\epsilon_{t}$. Iterating backwards recursively for $y_{t+h}$, we get $y_{t+h}=\tilde{\mu}+\frac{1-\phi^{h}}{1-\phi} y_{t}-\phi \frac{1-\phi^{h}}{1-\phi} y_{t-1}+\widetilde{c_{t}}$, where $\tilde{\mu}$ is a compound term for the mean. The log likelihood for the unrestricted model is -698.749 and the (conventional) BIC is 5.389 and the AIC is 5.349. If we estimate a restricted version of the Hamilton model where the coefficients on $y_{t}, y_{t-1}$ are restricted using the estimated $\hat{\phi}=$ 0.34 for an AR(1) model for $\Delta y_{t}$, the log likelihood is -705.76 , and the (conventional unscaled) BIC and AIC are 5.378 and 5.311 respectively, indicating that the information criteria would again prefer an AR(1) model, albeit not as strongly as in the HP filter case. Furthermore, for the unrestricted Hamilton model, we could not reject the null that the coefficients were equal to the coefficients implied by the AR(1) model (p-value 0.493).
} 
Furthermore, as pointed out by Nelson (2008), the notion of an output gap as a measure economic slack directly implies that it should have a negative forecasting relationship with future output growth. Specifically, when the economy is above trend and the output gap is positive, future growth should be below average as the economy returns to trend and vice versa. Motivated by the analysis in Nelson (2008), we calculate the correlation between a given estimate of the output gap and the subsequent 4-quarter output growth. ${ }^{9}$ Table 2 reports these correlations and, consistent with the findings in Nelson (2008), the correlation for the US output gap based on the AR(1) model is negative, while the correlation for the UC-HP model is positive. This result directly suggests that the output gap based on the AR(1) model provides a more accurate measure of economic slack than a UC-HP model, even if its relationship with recessions seems counterintuitive.

The remaining panels of Figure 2 plot the estimated output gaps based on the AR(1), UC-HP, and Hamilton gaps for real GDP data for the other nine industrialized economies in our sample. The estimates make it clear that the very different implications of the different models for the estimated output gap are not just a quirk of the US data. As in the US case, the output gap based on the AR(1) model is always smaller in amplitude than the output gap based on the UC-HP and Hamilton models and often of the opposite sign. The correlation results for these other economies in Table 2 are a bit more mixed, but the correlation with future output growth is still negative for more of the AR(1) and Hamilton model output gaps than for the UC-HP model output gaps. While the correlation of the Hamilton gap with future output growth is also negative, formal model comparisons, including comparisons based on AIC or SIC, still favor the AR(1) model.

\footnotetext{
${ }^{9}$ Nelson (2008) considers regressions that capture the correlation between a given estimate of the output gap and 1quarter-ahead US output growth. Our results for the US data are qualitatively similar to his even though we consider 4-quarter-ahead output growth, which arguably provides a better sense of forecasting ability at a policy-relevant horizon. Also, Nelson (2008) conducts a pseudo out-of-sample forecasting analysis by estimating models and output gaps using data only up to when the forecast is made (it is a pseudo out-of-sample forecast because the data are revised, although Orphanides and van Norden (2002) find that using revised or real-time data matters much less than incorporating future data in estimation of the output gap at any point in time). However, even though we use the whole sample to estimate models, we are implicitly using data only up to when the forecast is made to estimate output gaps. This is straightforward for the Harvey and Jaeger (1993) UC-HP model, which directly allows for filtered inferences, as opposed to the traditional HP filter, which is a two-sided filter, explaining why Nelson (2008) considers the out-of-sample forecasting analysis when evaluating the forecasting properties of the output gap based on the traditional HP filter.
} 
More favorable to the UC-HP model is the forecasting relationship between the competing model-based output gaps and future inflation. Table 3 reports correlations between output gap estimates and other macroeconomic variables, including the subsequent 4-quarter changes in inflation. Consistent with most conceptions of the Phillips curve, the correlation is always positive for the UC-HP model output gap, larger than the correlation for the Hamilton gap for 6 out of the 10 economies, and very close in magnitude to the correlations of the Hamilton gap for the remaining 4 cases. By contrast, it is negative for 8 out of 10 economies when considering the AR (1) model output gap.

Taken together, these results in Tables 2 and 3 suggest that the empirical evidence that a single forecast-based or regression-based estimate of the output gap provides a particularly accurate measure of economic slack is mixed at best. Put another way, even if we restrict ourselves only to three widely-used linear models, there is considerable uncertainty about the appropriate measure of economic slack. The AR(1) model fits the data better and its corresponding output gaps generally provides better forecasts of future real GDP growth. But the UC-HP model and the Hamilton output gaps are more consistent with widely-held beliefs about the relationship between economic slack and recessions and generally provide a better forecast of future changes in inflation.

Given the fact that the AR(1), the UC-HP model, and the Hamilton gap model are linear, a natural question that arises is whether accounting for any potential nonlinearities would provide a better measure of the business cycle and economic slack. While nonlinear models are more highly parametrized, there is some evidence that nonlinear models fit US output growth better than the corresponding linear AR(p) models (see, for example, Hamilton, 1989, or Kim, Morley, and Piger, 2005). Table A.3 in the appendix presents the results of the Carrasco, Hu, and Ploberger (2014) test for a test for Hamilton (1989) and bounceback Markov-switching models with normal and $t$-distributed errors versus a linear AR(2) model and a Monte-Carlo based likelihood ratio (LR) test for a depth-based bounceback model versus an AR(2) model (these models are discussed in more detail in the next section). Again, the results are inconclusive in many cases, with the test statistics being right around the threshold critical values in many cases and the results being sensitive to the assumptions about the distribution of the disturbances. 
These mixed results for different models motivate the methods outlined in the next section. In particular, drawing from an insight going back at least to Bates and Granger (1969) that combined forecasts can outperform even the best individual forecast, we follow and simplify the approach in Morley and Piger (2012) by constructing a model-averaged estimate of the output gap with equal weights over a range of linear and nonlinear forecasting models.

\section{Methods}

Our methods build on the approach to estimating a model-averaged output gap (MAOG) developed in Morley and Piger (2012) for US real GDP. Relative to the earlier study, we consider a few important modifications that make the approach easier to consider for data for other economies, and that, in some cases as discussed below, lead to improved estimates of the output gap when it comes to coherence with other measures of economic slack.

As background for our approach, we define the output gap, $c_{t}$, as the deviation of log real GDP, $y_{t}$, from its stochastic trend, $\tau_{t}$, as implied by the following trend/cycle process:

$$
\begin{gathered}
y_{t}=\tau_{t}+c_{t}, \\
\tau_{t}=\tau_{t-1}+\eta_{t}^{*}, \\
c_{t}=\sum_{j=0}^{\infty} \psi_{j} \omega_{\mathrm{t}-\mathrm{j}}^{*},
\end{gathered}
$$

where $\psi_{0}=1, \eta_{t}^{*}=\mu+\eta_{t}$ and $\omega_{t}^{*}=\bar{\omega}+\omega_{t}$, with $\eta_{t}$ and $\omega_{t}$ following martingale difference sequences. The trend, $\tau_{t}$, is the permanent component of $y_{t}$ in the sense that the effects of the realized trend innovations, $\eta_{t}^{*}$, on the level of the time series are not expected to be reversed. By contrast, the cycle, $c_{t}$, which captures the output gap, is the transitory component of $y_{t}$ in the sense that the Wold coefficients, $\psi_{j}$, are assumed to be absolutely summable such that the realized cycle innovations, $\omega_{t}^{*}$, have finite memory. The parameter $\mu$ allows for non-zero drift in the trend, while the parameter $\bar{\omega}$ allows for a non-zero mean in the cycle, although the mean of the cycle is not identified from the behaviour of the time series alone, as different values for $\bar{\omega}$ all imply the same reduced-form dynamics for $\Delta y_{t}$, with the standard identification assumption being that $\bar{\omega}=0$. 
The optimal estimate (in a minimum mean-squared-error sense) of trend for a range of trend/cycle processes as in (1)-(3), including those with regime-switching parameters, can be calculated using the regime-dependent steady-state (RDSS) approach developed in Morley and Piger (2008). The RDSS approach involves constructing long-horizon forecasts using a given time series model to capture the dynamics of the process. Importantly, the long-horizon forecasts are conditional on sequences of regimes and then marginalized over the distribution of the unknown regimes. Specifically, the RDSS measure of trend is

$$
\begin{aligned}
& \hat{\tau}_{t}^{R D S S} \equiv \sum_{\tilde{S}_{t}}\left\{\hat{\tau}_{t}^{R D S S}\left(\tilde{S}_{t}\right) * p^{M}\left(\tilde{S}_{t} \mid \Omega_{t}\right)\right\} \\
& \hat{\tau}_{t}^{R D S S}\left(\widetilde{S_{t}}\right)=\lim \left\{E^{M}\left[y_{t+j} \mid\left\{S_{t+k}=i^{*}\right\}_{k=1}^{j}, \underset{j \rightarrow \infty}{\widetilde{S_{t}}}, \Omega_{t}\right]-j * E^{M}\left[\Delta y_{t} \mid\left\{S_{t}=i^{*}\right\}_{-\infty}^{\infty}\right)\right\}
\end{aligned}
$$

where $\widetilde{S_{t}}=\left\{S_{t}, \ldots, S_{t-m}\right\}^{\prime}$ is a vector of relevant current and past regimes for forecasting a time series, $p^{M}(*)$ is the probability distribution with respect to the forecasting model, $S_{t}$ is an unobserved state variable that takes on $N$ discrete values according to a fixed transition matrix, and $i^{*}$ is the "normal" regime in which the mean of the transitory component is assumed to be zero. The choice of "normal" regime $i^{*}$ is necessary for identification. Meanwhile, for a given forecasting model with Markov-switching parameters, the probability weights in (4), $p^{M}\left(\widetilde{S}_{t} \mid \Omega_{t}\right)$, can be obtained from the filter given in Hamilton (1989). Note that the RDSS trend simplifies to the $\mathrm{BN}$ trend in the absence of regime switching.

In practice, the correct model for the dynamics of the time series process is unknown. Thus, we consider a range of models. Like Morley and Piger (2012), we focus on univariate models of real GDP, which in our case include the AR(1), UC-HP, and Hamilton (2018) models discussed in the previous section. As is evident from Figure 2, these univariate models capture a range of possibilities about the nature of the output gap. Also, univariate analysis allows us to test multivariate relationships rather than assume the answer a priori. The benefits of this approach for the relationship with inflation in particular will become evident when the results are presented below.

All of the models we consider allow for a stochastic trend in real GDP, which is motivated by standard unit root and stationarity tests, even when allowing for structural breaks in long-run 
growth. The results for all of the countries for pre-tests that entail standard unit root tests (Augmented Dickey-Fuller and Elliott-Rothenberg-Stock point-optimal Dickey Fuller), the standard stationarity tests (Leybourne and McCabe, 1992, and the KPSS test proposed by Kwiatkowski et al., 1992), and the unobserved-components based stationarity test from Morley, Panovska, and Sinclair (2017) are presented in Table A.4 in the appendix. ${ }^{10}$ This is important because many off-the-shelf methods such as linear detrending, traditional HP filtering, and Bandpass filtering produce large spurious cycles when applied to time series with stochastic trends (see Nelson and Kang, 1981, Cogley and Nason, 1995, Murray, 2003, and Hamilton, 2018). By contrast, as long as the models under consideration avoid overfitting the data, the forecast-based approach will not produce large spurious cycles.

We consider linear AR(p) models of orders $p=1,2,4,8$, and 12, the linear UC-HP model due to Harvey and Jaeger (1993), the Hamilton (2018) model, linear UC0 and UCUR models with AR(2) cycles from Morley, Nelson, and Zivot (2003), the nonlinear bounceback (BB) models from Kim, Morley, and Piger (2005) with BBU, BBV, and BBD specifications and AR(0) or AR(2) dynamics, the nonlinear UC0-FP model with an AR(2) cycle from Kim and Nelson (1999), and the nonlinear UCUR-FP model with an AR(2) cycle from Sinclair (2010). ${ }^{11}$

The linear and nonlinear AR(p) models are specified as follows:

$$
\phi(L)\left(\Delta y_{t}-\mu_{t}\right)=e_{t}
$$

\footnotetext{
${ }^{10}$ Based on the Monte Carlo analysis in Morley, Panovska, and Sinclair (2017), we consider the bootstrapped $p$ values for all stationarity tests to correct for potential size distortions in finite samples.

${ }^{11}$ As a minor modification from Morley and Piger (2012), we drop the linear AR(0) models and nonlinear Markovswitching model from Hamilton (1989) with $\operatorname{AR}(0)$ and $\operatorname{AR}(2)$ dynamics. In the former case, the output gap is always zero by construction, so its inclusion merely serves to shrink the model-averaged output gaps towards zero. In the latter case, the output gap is linear by construction, so its inclusion as a nonlinear model puts additional prior weight on a linear output gap. As demonstrated below, dropping these models has very little practical impact on the model-averaged estimate of the output gap for US real GDP. If the Hamilton (1989) model is included in the set of models, the correlation between the MAOG computed using equal weights that includes the Hamilton Model and the MAOG that does not include the Hamilton (1989) model is 0.99. Furthermore, as shown in Table A.4, the Carrasco et al. (2014) bootstrap test for Markov-Switching parameters cannot reject the null of no switching for all economies except New Zealand, Italy, and Australia, with p-values higher than $10 \%$ in all cases except for Italy. However, the null of linearity can be strongly rejected in favor of the BBD model for those three economies. The null of linearity can also be rejected in favor of the BBU model for Germany, Japan, Korea, New Zealand, and the UK, and in favor of the BBD model for all economies except Italy and New Zealand. Therefore, our set of models does not lose empirical relevance by excluding the Hamilton (1989) model.
} 


$$
\mu_{t}=\mu\left(S_{t}, \ldots, S_{t-m}\right)
$$

where $\phi(L)$ is $p^{\text {th }}$ order. We consider versions of the $\mathrm{AR}(\mathrm{p})$ models with Gaussian errors (i.e., $e_{t} \sim N\left(0, \sigma_{e}^{2}\right)$ or Student $t$ errors (i.e., $e_{t} \sim t\left(v, 0, \sigma_{e}^{2}\right)$. For the nonlinear AR(p) models, $S_{t}=\{0,1\}$ is a Markov state variable with fixed continuation probabilities $\operatorname{Pr}\left[S_{t}=0 \mid S_{t-1}=0\right]=p_{00}$ and $\operatorname{Pr}\left[S_{t}=1 \mid S_{t-1}=1\right]=p_{11}$. In the linear case, $\mu_{t}=\mu$, while there are three different specifications of $\mu_{t}$ in the nonlinear case that correspond to the BB models developed by Kim, Morley, and Piger (2005):

1. "U"-Shaped Recessions (BBU)

$$
\mu_{t}=\gamma_{0}+\gamma_{1} S_{t}+\lambda \sum_{j=1}^{m} \gamma_{1} S_{t-j}
$$

2. "V"-Shaped Recessions (BBV)

$$
\mu_{t}=\gamma_{0}+\gamma_{1} S_{t}+\left(1-S_{t}\right) \lambda \sum_{j=1}^{m} \gamma_{1} S_{t-j}
$$

3. Recovery based on "Depth" (BBD)

$$
\mu_{t}=\gamma_{0}+\gamma_{1} S_{t}+\lambda \sum_{j=1}^{m}\left(\gamma_{1}+\Delta y_{t-j}\right) S_{t-j}
$$

where the state $S_{t}=1$ is labeled as the low-growth regime by assuming $\gamma_{1}<0$. Following Kim, Morley, and Piger (2005), we assume $m=6$. See the original study for the full motivation of these specifications.

The linear and nonlinear UC models are based on (1)-(3), with the following parametric specification of the transitory component in (3):

$$
\phi(L) c_{t}=\omega_{t}^{*}
$$

where $\bar{\omega}=0$ for the linear UC0 and UCUR models and $\bar{\omega}=\tau S_{t}$ for the nonlinear UC0-FP and UCUR-FP models, with the state $S_{t}=1$ labelled by assuming $\tau<0$. The shocks to the trend and cycle are Gaussian (i.e., $\eta_{t} \sim N\left(0, \sigma_{\eta}^{2}\right), \omega_{t} \sim N\left(0, \sigma_{\omega}^{2}\right)$ ), for the UC0 and UC0-FP models and $\left(\eta_{t}, \omega_{t}\right)^{\prime} \sim N\left(0, \Sigma_{\eta \omega}\right)$, for the UCUR and UCUR-FP models). Given an AR(2) cycle, the covariance for the UCUR and UCUR-FP models is identified (see Morley, Nelson, and Zivot, 2003). 
Bayesian estimates for these models are based on the posterior mode. Importantly, the prior for bounceback coefficient has zero mean, implying a prior mean of zero for the output gap. The prior for the mean of the transitory shock for the UC-FP models has a negative mean, but this has very little impact on the prior mean of the model-averaged output gap given the small weight on any given model. The prior on the AR coefficients keeps them in the stationary region. Finally, the prior for the continuation probabilities is centered at 0.95 for the expansion regime and 0.75 for the other regime. This is calibrated based on the results for US data in Morley and Piger (2012). The details of the priors for the various model parameters are set out in Table A.5 in the appendix.

In practice, given parameter estimates, we use the $\mathrm{BN}$ decomposition or, in the case of the UC models, the Kalman filter to estimate the output gap for the linear models. We use a linear regression for the Hamilton (2018) model. Note that the filtered inferences from the Kalman filter are equivalent to the $\mathrm{BN}$ decomposition using the corresponding reduced-form of the UC model, while the BN decomposition is equivalent to the RDSS approach in (4)-(5) in the absence of regime-switching parameters. To estimate the output gap for the nonlinear forecasting models, we use the RDSS approach or, in the case of the nonlinear UC models, the Kim (1994) filter, which combines the Kalman filter with Hamilton's (1989) filter for Markov-switching models. For the nonlinear models, we follow Kim and Nelson (1999) and Sinclair (2010) by assuming the "normal" regime $i^{*}=0$, which corresponds to an assumption that the cycle is mean zero in expansions.

Finally, the MAOG is calculated as follows:

$$
c_{t}=\sum_{i=1}^{N} c_{i, t} * \operatorname{Pr}\left(M_{i}\right)
$$

where $i$ indexes the $N$ models under consideration, $c_{i, t}$ is the estimated output gap for model $i$, $M_{i}$ is an indicator for model $i$, and $\operatorname{Pr}\left(M_{i}\right)$ denotes the weight placed on model $i$. In contrast to Morley and Piger (2012), who consider weights based on SIC to approximate Bayesian model averaging (BMA), we place equal weight on all models with $c_{i t}=\frac{1}{N}$, where $N$ is the total number of models under consideration. Given 14 linear models (five linear AR models with two types of errors, three linear UC models, and Hamilton's regression model) and 14 nonlinear 
models (two nonlinear AR models with three BB specifications and two types of errors and two nonlinear UC models), the weight on each model is $3.57 \%$.

Although a number of models receive nontrivial weight based on the SIC approximation of BMA when considering the US data in Morley and Piger (2012), this is not always the case for other economies. For example, a simple AR(0) (i.e., random walk model for levels) model would receive all weight for Australian real GDP both based on SIC and on log scores if it were included in the model set. However, such a model implies the output gap is always exactly zero by construction (not just zero on average), which clearly runs contrary to widely and strongly held beliefs. In the case of Japan, an AR(1) model would receive all weight for Japanese real GDP based on SIC and on log scores weights, and it also received all the weight at all points in time when we considered a more general specification where the weights were selected optimally using the SIC approximation and allowed to vary over time. As shown in Figure 2, this would imply that the largest deviation of Japanese output from its long-run trend over the last 60 years was about 0.02 percentage points, and that output in Japan was increasing during the Asian financial crisis. Similarly, BMA places all of the weight on an AR(1) model for Italy, which would imply that the Italian economy was substantially above potential during the Global Financial Crisis. As shown in detail in Tables 2 and 3, the simple model with fixed equal weights performs well for all economies, and in many cases we found it outperformed models with statistically optimal weights both when it came to matching more narrow measures of slack, and much more importantly, when it came to the link with future output growth.

The problem of BMA putting too much weight (from a forecasting perspective) on one model has been highlighted by Geweke and Amisano (2011). They find that linear pooling of models produces better density forecasts than BMA and discuss the calculation of optimal weights for linear pooling of models. However, as long as the model set is relatively diverse, applying equal weights to models works almost as well as optimal weights and is much easier to implement in practice. Thus, we take this simple approach of using equal weights for the reasonably diverse set of linear and nonlinear models discussed above. ${ }^{12}$ In general, even though in this study we

\footnotetext{
12 To be specific, we place equal weights on all models used here. Because the nonlinear models nest linear dynamics in their parameter space, there is still more implicit prior weight on linear than nonlinear dynamics, although this is addressed somewhat by the somewhat informative priors for parameters in the nonlinear models.
} 
focus on industrialized economies, being aware of potential problems when BMA puts too much weight on one model and leads to counterintuitive estimates could be particularly important in cases when researchers are estimating output gaps for countries where the previous literature is relatively scarce and the researchers do not have additional information about the shape of the business cycle or do not have additional data or only have limited data about unemployment rates or other measures of economic activity.

The other major modification from Morley and Piger (2012) mentioned above is that models are estimated using Bayesian methods instead of maximum likelihood estimation (MLE). This allows incorporation of informative priors in the estimation. The priors we used here are not particularly strong, with estimates based on the posterior mode virtually identical to MLE for many of the models. ${ }^{13}$ However, for economies with relatively short samples for real GDP or other quirks in the data such as large outliers, there appears to be some tendency for MLE of the UC models and the nonlinear models to overfit the data. By incorporating more informative priors about the persistence of the autoregressive dynamics or the persistence of Markovswitching regimes based on US estimates from Morley and Piger (2012), we are able to avoid problems associated with shorter samples and outliers, while obviating the need to undertake a long, protracted search for the best model specifications for each economy. ${ }^{14}$

\section{Results}

We first consider the United States as a benchmark case in order to provide perspective on the impact of the modifications to Morley and Piger (2012) described in the previous section, as well as providing context for the results for other countries.

\footnotetext{
${ }^{13}$ The AR(1) and UC-HP models discussed in previous section were estimated using the posterior mode. But the estimated output gaps for these models are indistinguishable from those based on MLE. For example, for the US data, the correlation between the Bayesian and MLE output gaps is $>0.999999$.

${ }^{14}$ In principle, this setup would also make it possible to apply the approach outlined in this paper even given severe data limitations or a desire to impose tighter priors based on strongly held beliefs. For example, in an earlier version of this study, Morley (2014) estimated the output gap for a set of 13 economies in the Asia and Pacific, many with very short sample periods and extreme outliers. In terms of imposing tighter priors on characteristics such as the smoothness of trend, see the approaches outlined in Harvey, Trimbur, and van Dijk (2007) for UC models and Kamber, Morley, and Wong (2018) for AR models. However, given the strong evidence for a volatile stochastic trend in Morley, Panovska, and Sinclair (2017) and in Table A.4 in the appendix, we avoid imposing smoothness priors as it could potentially lead to spurious cycles.
} 
To begin, we compare the updated MAOG based on the US real GDP data described in Section 2, equal weights, and Bayesian estimation to the original MAOG reported in Morley and Piger (2012) based on a shorter sample period, a different vintage of data, BMA weights, and MLE. We also consider an updated MAOG based on BMA weights and MLE for the full sample. Figure 3 plots these three MAOGs together. The most noticeable thing is their similarity, with the major finding in Morley and Piger (2012) of a highly asymmetric shape holding for the updated MAOGs. The correlation between the updated MAOG based on BMA weights and MLE and the updated MAOG based on equal weights and Bayesian estimation is 0.95.

The impact of incorporating prior information about parameters may be obscured in Figure 3 given that the priors were calibrated in part based on previous estimates for US data. However, it is important to emphasize that the asymmetric shape of the output gap is in no way driven by the priors on the nonlinear models. As already discussed, because the nonlinear models nest linear dynamics in their parameter space, there is still more implicit prior weight on linear than nonlinear dynamics. Furthermore, the priors for the Markov-switching parameters favor regime shifts in the mean growth rate corresponding to business cycle phases, along the lines of Hamilton (1989), but there is no prior that shocks have more temporary effects in recessions than in expansions. However, to further illustrate that our estimation approach does not lead to spurious findings of nonlinearity, we perform a simulation experiment where we use a linear data-generating process calibrated to US data, and we apply our approach to estimating the output gap as deviations from the long-run trend. Figure 4 makes this clear by applying the modified approach to data simulated from a simple random walk with drift. ${ }^{15}$ For this data, the true output gap is always zero. The estimated average MAOG is not always zero, but, unlike what would be the case for the HP filter given a random walk, the spurious cycle is quite small in magnitude relative to the US MAOG, and it is smaller on average than the Hamilton regressionbased cycle. The main thing to note, however, is that the fluctuations are symmetric around zero. Thus, any finding of asymmetry for the MAOGs reflects the data, not the incorporation of prior information in estimating model parameters. ${ }^{16}$

\footnotetext{
15 The drift and standard deviation of shocks are both set to 1, which is a surprisingly reasonable calibration for 100 times the natural logs of quarterly US real GDP.

${ }^{16}$ In the simulation, when we use BMA weights, almost all of the weight is correctly assigned on the AR(1) model with very small amplitude and persistence (consistent with the true DGP that has no cycle). However, the average
} 
As displayed in Figure 3, our results indicate that there is little remaining economic slack for the US economy at the end of the sample. This result is consistent with the Federal Reserve's views (see, for example, Yellen, 2015). These results, however, turn out to be sensitive to allowing for a structural break in long-run growth in 2000Q3. As discussed in detail and illustrated in Figure A.S.1 in the supplemental online appendix, assuming no change in the long-run growth, the US economy appears to still be below trend at the end of the sample. Given uncertainty about the structural break, it could make sense to average across these two scenarios, which would still imply the economy remains slightly below trend at the end of the sample, although not by as much as in the no break case. If we assume that the US economy was at trend at the end of the sample, this would clearly imply that recessions can permanently shift the trend path of output downwards, which is the implication of many forecasting models for US real GDP, including low-order AR(p) models, Hamilton's (1989) Markov-switching model, and, to some extent, the bounceback models of Kim, Morley, and Piger (2005). In a recent paper, Huang, Luo, and Startz (2016) find that recessions prior to 1984 can be described as U-shaped, but recessions after 1984 can be better described using Hamilton's (1989) L-shaped model, where recessions are driven by permanent negative shocks. Figure 5 plots the estimated trend in US real GDP based on the model-averaged output gap. A permanent negative effect of the Great Recession of the trend path is quite evident for this estimate of trend and is much larger than for previous recessions. ${ }^{17}$

One way to judge the plausibility of the US economy being at trend at the end of the sample is to compare the US MAOG to other narrower measures of slack. Figure 6 plots the US MAOG against the US unemployment rate and US capacity utilization. Similar to the findings in Morley and Piger (2012), there is a clear relationship between the MAOG and these variables. More supportive of relatively little remaining slack at the end of the sample is the simple fact that the MAOG in the no break case would imply relatively fast growth and downward pressure on

\footnotetext{
MAOG cycle has a small amplitude and persistence and it does not create a spurious cycle with a large amplitude or spurious evidence of nonlinearity.

${ }^{17}$ Allowing for one structural break in 1973Q1 leads to similar results. Similarly, allowing for a structural break in 2000Q3 but not in 1973Q1 leads to an estimated MAOG that is large and negative during the 1990-1991 recession and very deep during 2001 recession, which is at odds with previous estimates of output slack, and with more narrow measures of slack, such as unemployment and capacity utilization, where both the 1990 and 2001 recession were relatively shallow. This further motivates our inclusion of a structural break in 1973Q1. We discuss these results in detail in the supplemental online appendix.
} 
inflation in the period immediately after the Great Recession. In particular, returning to Tables 2 and 3, the US MAOG has a negative correlation of -0.33 with future output growth and positive correlation of 0.49 with future changes in inflation. These results are much stronger than those for the output gaps based on the AR(1) and UC-HP models and stronger than those for the Hamilton gap and support the MAOG as a highly relevant measure of economic slack. But, given lacklustre growth and stable inflation after the Great Recession, these results also support the MAOG allowing for a structural break and the idea that the US economy is actually close to trend at the end of the sample, noting that the trend path is lower than before the recession, as suggested in Figure 5.

In principle, additional information from capacity utilization, the unemployment rate, or inflation could be used in the construction of output gaps. However, the estimates of the output gap obtained from multivariate models depend crucially on the assumptions about the relationship between the output gap and, for example, the labor market cycle, and on the assumptions about the stability of these relationships over time. For example, Basistha and Nelson (2007) and Gonzalez-Astudillo and Roberts (2018) estimate models where the unemployment cycle directly depends on the output cycle (and on inflation in Basistha and Nelson's model). In both cases the estimated output cycles that have large amplitude and large persistence. On the other hand, Sinclair (2009) estimates a bivariate UC model for output and unemployment where the shocks to the trend and the cycle for output and the unemployment rate are allowed to be correlated, but does not impose other links, and finds that most of the movements in output are driven by shocks to the permanent component.

There is also substantial evidence in favour of time-variability in the link between the narrower measures of slack and the output cycle. Panovska (2017) finds strong evidence that link between the output cycle and the labor market cycle changed abruptly in the mid 1980s. Similarly, Berger, Everaet and Vierke (2016) find very substantial time variation in the link between the unemployment cycle and the output cycle when using an unobserved components model. Similarly, the literature about whether one should impose a restriction that positive shocks to the output trend (productivity shocks) affect labor markets positively or negatively is also very large (see, for example, Barnichon, 2010). 
Given the fact that we report the correlations with the more narrow measures of slack to simply assess whether the measure of slack is reasonable and the fact that the empirical evidence on the stability in the links between the output gaps and other variables is quite conflicting, using a wide set of univariate models is a more agnostic approach than using a multivariate model that directly imposes a strong link between output and another variable, especially because our sample includes countries with various degrees of labor market rigidities, approaches to monetary policy conduct, and industrial compositions.

Having demonstrated how the modified approach works in the benchmark US case, at least when allowing for structural breaks in long-run growth, we now calculate MAOGs for the remaining G7 economies, Australia, New Zealand, and Korea.

Figure 7 plots the estimated output gaps for the nine other economies. For all cases considered, the output gaps are highly asymmetric, similar to the US results. Specifically, they take on much larger negative values than positive ones. The only possible exception is Italy, where the output fluctuations are relatively more symmetric, but there is still strong evidence that the contractions in 1969 and 2008-2009 caused highly asymmetric movements. The ubiquity of this form of business cycle asymmetry across the ten economies under consideration strongly suggests that it is an intrinsic characteristic in industrialized economies, not just a feature of the US economy in particular. This is a potentially important result for theory-based modelling of the business cycle, which tends to focus on linear dynamics for convenience, although there are many exceptions. ${ }^{18}$

How plausible are the MAOGs as measures of economic slack? As with the US benchmark, we compare the MAOGs to other narrower measures of slack. The middle panel of Table 3 reports the correlation of each MAOG with the corresponding unemployment rate. For comparison, we also report correlations for output gaps based on AR(1), UC-HP, and the Hamilton model. Corresponding to an Okun's Law relationship, the MAOG has the most negative correlation with

\footnotetext{
${ }^{18}$ For example, Diebold, Schorfheide, and Shin (2017) find that incorporating nonlinearities in the exogenous driving processes and allowing for stochastic volatility in a DSGE model markedly improves the density forecast performance of the model. Auroba, Bocola, and Schorfheide (2013) highlight the fact that asymmetric wage and price adjustments lead to inherent nonlinearity in DSGE models, and argue in favor of using a nonlinear time-series model to evaluate the performance and predictive ability of DSGE models. Guerrieri and Iacoviello (2016) find that collateral constraints in a DSGE model lead to macroeconomic asymmetries - in particular, when constraints are slack, expanding wealth makes small contribution to consumption growth, but tightened constraints can sharply exacerbate recessions.
} 
the unemployment rate in all 10 cases (including the US benchmark), with many of the correlations being quite large in magnitude. Meanwhile, the bottom panel of Table 3 reports the corresponding correlations with capacity utilization. The MAOG has the most positive correlation with capacity utilization in 6 out of 10 cases and has positive correlations in all of the other cases.

Overall, the strong coherence with other measures of slack lends credence to the MAOGs. The coherence is particularly notable given that the MAOGs are estimated using only univariate models of real GDP. At the same time, the MAOGs provide a broad and useful measure of slack, even when unemployment rate or capacity utilization data are distorted as pure measures of slack by long-run structural factors.

Much more importantly, revisiting Table 2, the MAOGs provide a stronger signal about future economic growth than the three other output gap estimates for all of the countries in our sample. This result provides the most direct support of the MAOGs as measures of economic slack based on the definition considered in this paper. It also confirms the possibility that output growth can be somewhat predictable even when standard model comparison metrics would select a random walk model, as the SIC would in the case of Australia.

Looking back at Table 3, the results for the MAOGs in terms of correlation with future changes in inflation are more mixed. The MAOGs provide a stronger signal than the UC-HP or Hamilton model output gap in only 4 of the 10 cases (including the US benchmark) and the Hamilton gap provides stronger signal than the other models for France and the United Kingdom. However, a correlation coefficient may be too simplistic as a measure of the relationship between the output gap and inflation. Figure 8 displays a scatterplot of the MAOG ( $x$-axis) against the subsequent 4quarter change in inflation ( $y$-axis). For many of the countries there is a clear nonlinear, convex Phillips Curve relationship between the output gap and future changes in inflation that would only be partially captured by a correlation coefficient. The same convex relationship as for the US data is evident for Australia, France, Japan, and Korea. For some of the other cases, such as Canada and New Zealand, the Phillips Curve relationships look more linear. However, a clear implication of Figure 8 is that it is important not to impose a linear (or any other) specification for the Phillips Curve relationship a priori, as is done in some other approaches to estimating output gaps (e.g., Kuttner, 1994). In particular, if the imposed relationship were incorrectly 
specified, then the resulting output gap estimate would necessarily be distorted and could not be used to determine a better specification of a Phillips Curve relationship. The convexity of the Phillips Curve in some cases argues against imposing a linear specification. Also, there is some evidence that the relationship between the output gap and inflation has evolved over time, with many of the observations of stable inflation following large negative output gaps corresponding to the recent Global Financial Crisis. Consistent with Lucas's (1976) famous critique that reduced-form Phillips Curve relationships should change with policy regimes, this apparent breakdown in the previous pattern near the end of the sample could be due to an anchoring of inflation expectations (see IMF, 2013) and argues strongly against imposing a fixed relationship with inflation when estimating the output gap.

\section{Robustness: Revision Properties and Comparison with Other Output Gaps}

\subsection{Revision Properties}

Given our key question of whether business cycles exhibit asymmetric behaviour, we believe the best approach to evaluation is based on the full information set. Therefore, our benchmark analysis made use of the longest available samples with revised data. However, output gaps are very frequently used for policy analysis and it is important to evaluate the performance of estimates in real time. This is particularly important in light of the studies by Orphanides and van Norden (2002) and Nikolsko-Rzhevskyy (2011), which show that popular methods of estimating the output gap are unreliable in real time both for the US and for other economies, respectively.

To evaluate the real-time performance of the MAOG, we compare it to the three other benchmark models considered in the previous subsections. In particular, we compare estimates obtained using real time data for the US case, for which real-time series are readily available. We use the real-time dataset from the Federal Reserve Bank of Philadelphia, and extract real GDP from the Core Variables/ Quarterly Observations/ Quarterly Vintages subset.

We note that it would be difficult to detect structural breaks in real time and allowing for breaks as done in our benchmark example was only feasible from an ex-post basis. To address this, we use dynamic demeaning as in Kamber, Morley, and Wong (2018). In particular, we demean the 
data using a backward-looking rolling 40-quarter average growth rate. The deviations from the mean were constructed as follows:

$$
\Delta \widetilde{y_{t}}=\Delta y_{t}-\frac{1}{40} \sum_{i=0}^{39} \Delta y_{t-i} .
$$

We use 40 quarters to smooth over the effects of business cycle fluctuations on average growth. As shown in the supplemental online appendix in Figure A.S.2, the MAOG estimates from the model with imposed breaks and from the model with dynamic demeaning have virtually identical patterns, extremely similar magnitude, and are very highly correlated, with the correlation coefficient being 0.997 .

Figure 9 plots the real-time and the revised estimate of the AR(1) output gap, the UC-HP output gap, the Hamilton gap, and the MAOG. Table 4 reports the correlation between the revised and real-time estimate for each of the four benchmark gaps, the standard deviation of the revision, and the standard deviation of the revision scaled by the standard deviation of the output gap estimate. In short, the MAOG performs quite well in real time. The MAOG calculated using real time data is highly correlated with the MAOG calculated using revised data (correlation 0.97). This correlation is much higher than the correlation between the HP gap calculated using real time data and revised data (0.61) and slightly higher than the correlation between the real time and the revised version of the Hamilton gap (0.94). Likewise, as also shown in Table 4, the standard deviation of the revisions is smaller for the MAOG than for the other output gap estimates. Notably, the MAOG captures the NBER recessions and turning points remarkably well both when using revised data and when using real time data.

\subsection{Comparison with Official Output Gap Estimates}

Given the wide use of non-statistical estimates of the output gap, such as, for example, the production-function-based $\mathrm{CBO}$ and OECD output gaps, it is of interest to examine how the MAOG behaves in comparison with these estimates.

Different official production-function-based estimates (for example, the CBO vs. the OECD estimates) of the output gap can display very different patterns both it terms of amplitude and persistence of the output gap and when it comes to exhibiting asymmetry, and the patterns 
depend on the assumptions used to specify the production function. Figure 10 plots the OECD estimate for the US output gap, the CBO estimate for the output gap, and the MAOG. As shown in the figure, the $\mathrm{CBO}$ estimate has much larger amplitude than the other two gaps and does not exhibit any significant degree of asymmetry, with the correlation between the CBO gap and our MAOG estimate being 0.6. By contrast, the OECD estimate, which is also estimated using a production function approach, has a smaller amplitude and exhibits asymmetry that is similar to the asymmetric pattern in the MAOG (the correlation between the OECD gap and the MAOG is $0.8) .{ }^{19}$

It is important to note too that both the CBO and the OECD gaps are subject to very heavy revisions. For example, Astudillo-Gonzalez (2017) points out that the CBO estimate of the output gap during the Great Recession got revised by as much as 2 percentage points. Of course, the $\mathrm{CBO}$ is only allowed to make projections under current law, with the projections usually using constant trend growth rates. A recent study by Coibion, Gorodnichenko, and Ulate (2017) also highlights that official cyclical estimates of output gaps are very sensitive to assumptions about changes in the trend growth and the nature of permanent shocks.

\section{Conclusions}

There is more uncertainty about the degree of economic slack than is commonly acknowledged in academic and policy discussions, which often treat the output gap as if were directly observed. Canova (1998) argues that this uncertainty has huge implications in terms of "stylized facts" about the business cycle used to motivate theoretical analysis.

In light of this uncertainty about the degree of economic slack, we propose a model-averaged forecast-based estimate of the output gap. For all of the industrialized economies considered in our analysis, the model-averaged estimate is closely related to narrower measures of slack and,

\footnotetext{
19 Similarly, the OECD estimates of the output gap for the other G7 economies, for which data is readily available at quarterly frequency, tend to exhibit quite a bit of asymmetry, with negative movements being larger in magnitude but less persistent than positive movements. Our MAOG estimates also appear to match the turning points in the OECD estimates quite well. The correlations of these estimates with our MAOG estimates range from 0.6 for Italy to 0.8 for the US, with the UK being the only outlier with the correlation of only 0.4 . The full set of results is available from the authors upon request.
} 
consistent with the notion of an output gap as a measure economic slack, has a strong negative forecasting relationship with future output growth. Most importantly, the model-averaged output gap estimates are all highly asymmetric. A simulation experiment where we estimate output gaps for linear models confirms that our findings of nonlinearity are not spurious or driven by the fact that we include nonlinear models in our set of models. In simulations where the true DGP is symmetric, our estimates are symmetric. This directly suggests that this particular form of business cycle asymmetry observed in the data is intrinsic in industrialized economies and should be addressed in theoretical models of the economy. ${ }^{20}$

Evidence for a Phillips Curve relationship between the model-averaged output gap and inflation is more mixed. But the overall results strongly argue against imposing a linear relationship in estimating output gaps. As an example of why imposing a fixed relationship is so problematic, consider Stock and Watson $(2009,2010)$. Their analysis suggests that inflation is difficult to forecast using standard measures of economic slack, except when the estimated output gap (or unemployment gap) is large in magnitude. This directly suggests possible mismeasurement due to imposition of symmetry and/or a nonlinear Phillips Curve relationship (see Dupasquier and Ricketts, 1998, and Meier, 2010). Our measure of economic slack allows for a full investigation of the nature of the relationship between the output gap and inflation, including the possibility of nonlinearity.

\footnotetext{
${ }^{20}$ As emphasized in Kiley (2013) and noted by many others, theory-oriented DSGE models imply reduced-form VAR, VECM, or VARMA models. Thus, forecast-based output gap estimates provide robust measures of economic slack across a wide range of different economic assumptions used to identify a structural model, at least as long as the reduced-form model or models used to calculate the optimal forecast capture the dynamics in the data (this point relates back to Sims, 1980_-also see Fernandez-Villaverde et al., 2007).
} 


\section{References}

Auroba, S. Boragan, Luigi Bocola, and Frank Schorfheide, 2013, “Assessing DSGE Model Nonlinearities," Federal Reserve Bank of Philadelphia Working Paper No. 13-47.

Bai, Jushan, and Pierre Perron, 1998, "Estimating and Testing Linear Models with Multiple Structural Changes," Econometrica 66, 47-78.

Bai, Jushan, and Pierre Perron, 2003, "Computation and Analysis of Multiple Structural Change Models," Journal of Applied Econometrics 18, 1-22.

Barnichnon, Regis, 2010, "Productivity and Unemployment over the Business Cycle," Journal of Monetary Economics 57, 1013-1025.

Basistha, Arabinda and Charles R. Nelson, 2007, "New Measure of the Output Gap Based on the Forward-Looking New Keynesian Phillips Curve.” Journal of Monetary Economics, 54, 498-511.

Bates, John M., and Clive W.J. Granger, 1969, "The Combination of Forecasts," Operations Research Quarterly 20, 451-468.

Berger, Tino, Gerdie Everaet, and Hauke Vierke, 2016, "Testing For Time Variation in an Unobserved Components Model for the US Economy." Journal of Economic Dynamics and Control 69, 179-208.

Beveridge, Stephen, and Charles R. Nelson, 1981, "A New Approach to Decomposition of Economic Time Series into Permanent and Transitory Components with Particular Attention to Measurement of the Business Cycle," Journal of Monetary Economics 7, 151-174.

Canova, Fabio, 1998, "Detrending and Business Cycle Facts," Journal of Monetary Economics 41, 475512.

Carrasco, Marine, Liang Hu, and Werner Ploberger, 2014, "Optimal Test for Markov Switching Parameters," Econometrica 82, 765-784.

Clark, Peter K, 1987, “The Cycle Component of the U.S. Economic Activity," Quarterly Journal of Economics 102,797-814.

Cogley, Timothy, and James M. Nason, 1995, "Effects of the Hodrick-Prescott Filter on Trend and Difference Stationary Time Series: Implications for Business Cycle Research," Journal of Economic Dynamics and Control 19, 253-278.

Coibion, Olivier, Yuriy Gorodnichenko, and Mauricio Ulate (2017): “The Cyclical Sensitivity in Estimates of Potential Output.” NBER Working Paper 23580.

Davidson, Russell, and James G. MacKinnon, 2004, Econometric Theory and Methods (New York: Oxford University Press).

De Jong, Robert M. and Neslihan Sakarya, 2016, "The Econometrics of the Hodrick-Prescott Filter". Review of Economics and Statistics 98, 310-317.

Dickey, David. A. and Wayne A. Fuller,1979, "Distribution of the estimators for autoregressive time series with a unit root," Journal of the American Statistical Association 74, 427-431.

Diebold, Francis X., Frank Schorfheide, and Minchul Shin, 2017, "Real-Time Forecast Evaluation of DSGE Models with Stochastic Volatility," Journal of Econometrics , 201, 322-332.

Dupasquier, Chantel, and Nicholas Ricketts, 1998, "Non-Linearities in the Output-Inflation Relationship: Some Empirical Results for Canada," Bank of Canada Working Paper 98-14. 
Elliott, Graham, Thomas. J. Rothenberg, and James H. Stock, 1996. "Efficient tests for an autoregressive unit root," Econometrica 64,813-836.

Fernandez-Villaverde, Jesus, Juan F. Rubio-Ramirez, Thomas J. Sargent and Mark W. Watson, 2007, “ABCs (and Ds) of Understanding VARs," American Economic Review 97(3), 1021-1026.

Garratt, Anthony, James Mitchell, and Shaun P. Vahey, 2014, "Measuring Output Gap Nowcast

Uncertainty," International Journal of Forecasting 30, 268-279.

Gonzalez-Astudillo, Manuel (2017): “GDP Trend-cycle Decompositions Using state-level Data” Federal Reserve Board Working Paper.

Gonzalez-Astudillo, M. and J. Roberts (2018) “When Can Trend Cycle Decompositions Be Trusted?"

Federal Reserve Board Working Paper 20016-099.

Geweke, John, and Gianni Amisano, 2011, "Optimal Prediction Pools," Journal of Econometrics 164, $130-141$.

Guerrieri, Luca, and Matteo Iacoviello, 2016, “Collateral Constraints and Macroeconomic Asymmetries," Federal Reserve Board Working Paper.

Hamilton, James D., 1989, "A New Approach to the Economic Analysis of Nonstationary Time Series and the Business Cycle," Econometrica 57, 357-384.

Hamilton, James D. , 2018, "Why You Should Never Use the Hodrick-Prescott Filter" (forthcoming) Review of Economics and Statistics.

Harvey, Andrew C. and Albert Jaeger, 1993, "Detrending, Stylized Facts and the Business Cycle," Journal of Applied Econometrics 8, 231-247.

Harvey, Andrew C., Thomas M. Trimbur, and Herman K. Van Dijk, 2007, "Trends and Cycles in Economic Time Series: A Bayesian Approach,” Journal of Econometrics 140, 618-649.

Hodrick, Robert J. and Edward C. Prescott, 1997, "Postwar US Business Cycles: An Empirical Investigation," Journal of Money, Credit, and Banking 29,1-16.

Huang, Yu-Fan, Sui Luo and Richard Startz, 2016, "Are Recoveries All the Same: GDP and TFP?" University of California Santa Barbara Working Paper.

IMF, 2013, World Economic Outlook "Hopes, Realities, Risks" Chapter 3, International Monetary Fund.

Kamber, Gunes, James Morley, and Benjamin Wong, 2018, "Intuitive and Reliable Estimates of the Output Gap from a Beveridge-Nelson Filter." (forthcoming) Review of Economics and Statstics.

Kiley, Michael T., 2013, “Output Gaps,” Journal of Macroeconomics, 37, 1-18.

Kim, Chang-Jin, 1994, “Dynamic Linear Models with Markov Switching,” Journal of Econometrics 60, $1-22$.

Kim, Chang-Jin, James Morley, and Jeremy Piger, 2005, "Nonlinearity and the Permanent Effects of Recessions," Journal of Applied Econometrics 20, 291-309.

Kim, Chang-Jin, and Charles R. Nelson, 1999, "Friedman's Plucking Model of Business Fluctuations: Tests and Estimates of Permanent and Transitory Components," Journal of Money, Credit and Banking 31, 317-334.

Klinger, Sabine and Enzo Weber, 2016, "Detecting Unemployment Hysteresis: A Simultaneous Unobserved Components Model with Markov Switching," Economics Letters 114(c), 115-118. 
Kuttner, Kenneth N, 1994, "Estimating Potential Output as a Latent Variable," Journal of Business \& Economic Statistics 12, 361-68.

Kwiatkowski, Denis, Peter C. B. Phillips, Peter Schmidt and Yoncheol Shin, 1992, "Testing the Null Hypothesis of Stationarity Against the Alternative of a Unit Root," Journal of Econometrics 54, 159178.

Levin, Andrew, T. and Jeremy M. Piger, 2006, "Is Inflation Persistence Intrinsic in Industrial Economies?” University of Oregon Working Paper.

Leybourne, Stephen, J. and Brendan P. M. McCabe, 1992, "Testing the Null Hypothesis of Stationarity Against the Alternative of a Unit Root," Journal of Econometrics 64, 159-178.

Lucas, Robert E., 1976, "Economic Policy Evaluation: A Critique," Carnegie-Rochester Conference Series on Public Policy 1, 19-46.

Meier, André, 2010, "Still Minding the Gap - Inflation Dynamics during Episodes of Persistent Large Output Gaps,” IMF Working Papers 10/189, International Monetary Fund.

Morley, James, 2014, "Measuring Economic Slack: A Forecast-Based Approach with Applications to Economies in Asia and the Pacific." BIS Working Paper, No. 451.

Morley, James, Charles R. Nelson, and Eric Zivot, 2003, "Why Are the Beveridge-Nelson and Unobserved-Components Decompositions of GDP So Different?" Review of Economics and Statistics $85,235-243$.

Morley, James, Irina B. Panovska, and Tara M. Sinclair (2017), "Testing Stationarity with Unobserved Components Models," Macroeconomic Dynamics 21, 160-182.

Morley, James, and Jeremy Piger, 2008, "Trend/Cycle Decomposition of Regime-Switching Processes," Journal of Econometrics 146, 220-226.

Morley, James, and Jeremy Piger, 2012, "The Asymmetric Business Cycle," Review of Economics and Statistics 94, 208-221.

Murray, Christian J., 2003, "Cyclical Properties of Baxter-King Filtered Time Series," Review of Economics and Statistics 85, 472-476.

Nelson, Charles R., 2008, “The Beveridge-Nelson Decomposition in Retrospect and Prospect," Journal of Econometrics 146, 202-206.

Nelson, Charles R., and Heejoon Kang, 1981, "Spurious Periodicity in Inappropriately Detrended Time Series," Econometrica 49, 741-751.

Nelson, Charles R. and Plosser, Charles, 1982, "Trends and random walks in macroeconmic time series: Some evidence and implications," Journal of Monetary Economics 10, 139-162.

Nikolsko-Rzhevskyy, Alex, 2011, "Monetary Policy Estimation in Real Time: Forward-Looking Taylor Rules without Forward-Looking Data.”Journal of Money, Credit, and Banking, 43, 871-897.

Orphanides, Athanasios, 2002, "Monetary-Policy Rules and the Great Inflation," American Economic Review 92, 115-120.

Orphanides, Athanasios, and Simon van Norden, 2002, "The Unreliability of Output-Gap Estimates in Real Time," Review of Economics and Statistics 84, 569-583.

Panovska, Irina B., 2017, "What Explains the Recent Jobless Recoveries?," Macroeconomic Dynamics 21(3), 808-832.

Perron, Pierre, and Tatsuma Wada, 2009, "Let's Take a Break: Trends and Cycles in U.S. Real GDP," Journal of Monetary Economics 56, 749-765. 
Perron, Pierre and Tatsuma Wada, 2016, "Measuring Business Cycles with Structural Breaks and Outliers: Applications to International Data," Research in Economics 70, 281-303.

Sims, Christopher A., 1980, "Macroeconomics and Reality," Econometrica 48, 1-48.

Sinclair, Tara M, 2009, "The Relationships Between Permanent and Transitory Movements in U.S. Output and the Unemployment Rate," Journal of Money, Credit, and Banking, 41, 592-542.

Sinclair, Tara M., 2010, “Asymmetry in the Business Cycle: Friedman's Plucking Model with Correlated Innovations," Studies in Nonlinear Dynamics and Econometrics 14, Issue 1, Article 3.

Stock, James H., and Mark W. Watson, 2009, "Phillips Curve Inflation Forecasts," in Understanding Inflation and the Implications for Monetary Policy, a Phillips Curve Retrospective, Federal Reserve Bank of Boston.

Stock, James H., and Mark W. Watson, 2010, "Modeling Inflation after the Crisis," in Macroeconomic Challenges: The Decade Ahead, Federal Reserve Bank of Kansas City, 173-220. Kansas City, MO: Federal Reserve Bank of Kansas City.

Yellen, Janet L., 2015, The Economic Outlook and Monetary Policy. Speech at the Economic Club of Washington, D.C. December $2^{\text {nd }}, 2015$. http://www.federalreserve.gov/newsevents/speech/yellen20151202a.htm 


\begin{tabular}{|cccc|}
\hline \multicolumn{4}{c}{ Table 1 } \\
Structural Breaks in Long-Run Growth Rates of Real GDP \\
\hline & Sample Period & Break Dates & $\begin{array}{c}\text { Sequence of } \\
\text { Growth Regimes }\end{array}$ \\
\cline { 2 - 4 } United States & 1947Q2-2016Q1 & 1973Q1, 2000Q3 & H, M, L \\
Australia & 1959Q4-2015Q4 & - & - \\
Canada & 1960Q2-2015Q4 & 1974Q2 & H, L \\
France & 1949Q2-2016Q1 & 1974Q2 & H, L \\
Germany & 1960Q2-2016Q1 & 1973Q1, 1991Q2 & H, M, L \\
Italy & 1960Q2-2016Q1 & 1974Q1 & H, L \\
Japan & 1955Q2-2016Q1 & 1973Q1, 1991Q3 & H, M, L \\
Korea & 1970Q2-2016Q1 & 1997Q3 & H, L \\
New Zealand & 1977Q2-2016Q1 & - & - \\
United Kingdom & 1955Q2-2016Q1 & 1973Q2 & H, L \\
\hline
\end{tabular}

Notes: Estimated break dates are based on Bai and Perron's $(1998,2003)$ sequential procedure. Breaks are significant at least at $10 \%$ level. "H", "M", "L" denote high, medium, and low mean growth regimes, respectively. 


\begin{tabular}{|lccccc|}
\hline \multicolumn{5}{c}{ Correlation with Subsequent 4-Quarter Output Growth } \\
\hline & Sample Period & $\begin{array}{c}\text { AR(1) Model } \\
\text { Output Gap }\end{array}$ & $\begin{array}{c}\text { UC-HP Model } \\
\text { Output Gap }\end{array}$ & $\begin{array}{c}\text { Hamilton } \\
\text { Filter }\end{array}$ & $\begin{array}{c}\text { Model-Avg. } \\
\text { Output Gap }\end{array}$ \\
\cline { 2 - 6 } United States & 1947Q2-2015Q1 & -0.15 & 0.08 & -0.26 & $\mathbf{- 0 . 3 3}$ \\
Australia & 1959Q1-2014Q4 & -0.04 & -0.01 & -0.03 & $\mathbf{- 0 . 2 7}$ \\
Canada & 1960Q1-2014Q4 & -0.16 & -0.18 & -0.18 & $\mathbf{- 0 . 2 7}$ \\
Germany & 1960Q1-2015Q1 & -0.07 & -0.001 & -0.17 & $\mathbf{- 0 . 2 2}$ \\
France & 1949Q1-2015Q1 & -0.11 & 0.13 & 0.01 & $\mathbf{- 0 . 1 6}$ \\
Italy & 1960Q1-2015Q1 & -0.18 & 0.03 & -0.15 & $\mathbf{- 0 . 3 4}$ \\
Japan & 1955Q2-2015Q1 & 0.02 & 0.05 & -0.02 & $\mathbf{- 0 . 1 1}$ \\
Korea & 1970Q2-2015Q1 & -0.04 & -0.03 & -0.15 & $\mathbf{- 0 . 2 0}$ \\
New Zealand & 1977Q3-2015Q1 & 0.03 & 0.04 & 0.12 & $\mathbf{- 0 . 2 1}$ \\
United Kingdom & 1955Q2-2015Q1 & 0.21 & -0.22 & -0.26 & $\mathbf{- 0 . 3 5}$ \\
\hline
\end{tabular}




\begin{tabular}{|c|c|c|c|c|c|}
\hline \multicolumn{6}{|c|}{ Table 3 Correlation with Other Macroeconomic Variables } \\
\hline & \multicolumn{5}{|c|}{ Correlation with Subsequent 4-Quarter Change in Inflation } \\
\hline & Sample Period & $\begin{array}{l}\text { AR(1) Model } \\
\text { Output Gap }\end{array}$ & $\begin{array}{l}\text { UC-HP Model } \\
\text { Output Gap }\end{array}$ & Hamilton Filter & $\begin{array}{l}\text { Model-Avg. } \\
\text { Output Gap }\end{array}$ \\
\hline United States & 1960Q1-2015Q1 & -0.11 & 0.32 & 0.44 & 0.49 \\
\hline Australia & 1959Q4-2014Q4 & 0.20 & 0.35 & 0.30 & 0.38 \\
\hline Canada & 1960Q1-2014Q4 & -0.25 & 0.44 & 0.41 & 0.35 \\
\hline Germany & 1963Q1-2015Q1 & -0.21 & 0.49 & 0.09 & 0.12 \\
\hline France & 1971Q1-2015Q1 & -0.17 & 0.11 & 0.20 & -0.08 \\
\hline Italy & 1961Q1-2015Q1 & -0.26 & 0.19 & 0.08 & -0.29 \\
\hline Japan & 1961Q2-2015Q1 & 0.22 & 0.29 & 0.32 & 0.37 \\
\hline Korea & 1970Q2-2015Q1 & -0.12 & 0.31 & 0.27 & 0.40 \\
\hline New Zealand & 1977Q3-2015Q1 & -0.32 & 0.39 & 0.02 & 0.25 \\
\hline United Kingdom & 1957Q4-2015Q1 & -0.14 & 0.22 & 0.26 & 0.17 \\
\hline \multicolumn{6}{|c|}{ Note: Bold denotes the most positive correlation for each economy. } \\
\hline & \multicolumn{5}{|c|}{ Correlation with the Unemployment Rate } \\
\hline & Sample Period & $\begin{array}{l}\text { AR(1) Model } \\
\text { Output Gap }\end{array}$ & $\begin{array}{l}\text { UC-HP Model } \\
\text { Output Gap }\end{array}$ & Hamilton Filter & $\begin{array}{l}\text { Model-Avg } \\
\text { Output Gap }\end{array}$ \\
\hline United States & 1948Q1-2016Q1 & 0.05 & -0.14 & -0.57 & -0.68 \\
\hline Australia & 1978Q1-2015Q4 & 0.06 & -0.01 & -0.36 & $-\mathbf{0 . 4 3}$ \\
\hline Canada & 1960Q1-2015Q4 & -0.01 & -0.02 & -0.19 & -0.34 \\
\hline Germany & 1991Q1-2016Q1 & -0.03 & -0.11 & -0.27 & $-\mathbf{0 . 3 3}$ \\
\hline France & 1978Q1-2016Q1 & -0.01 & 0.05 & -0.14 & -0.36 \\
\hline Italy & 1983Q1-2016Q1 & -0.07 & 0.27 & -0.11 & -0.22 \\
\hline Japan & 1955Q3-2016Q1 & 0.02 & -0.05 & -0.11 & -0.22 \\
\hline Korea & 1990Q1-2016Q1 & -0.21 & 0.08 & -0.69 & -0.72 \\
\hline New Zealand & 1977Q3-2016Q1 & 0.00 & 0.19 & 0.40 & -0.47 \\
\hline United Kingdom & 1983Q1-2016Q1 & -0.16 & 0.20 & -0.13 & -0.42 \\
\hline \multicolumn{6}{|c|}{ Note: Bold denotes the most negative correlation for each economy. } \\
\hline & \multicolumn{5}{|c|}{ Correlation with Capacity Utilization } \\
\hline & Sample Period & $\begin{array}{l}\text { AR(1) Model } \\
\text { Output Gap }\end{array}$ & $\begin{array}{l}\text { UC-HP Model } \\
\text { Output Gap }\end{array}$ & Hamilton Filter & $\begin{array}{l}\text { Model-Avg } \\
\text { Output Gap }\end{array}$ \\
\hline United States & 1967Q1-2016Q1 & -0.08 & 0.27 & 0.62 & 0.52 \\
\hline Australia & 1989Q3-2016Q4 & 0.14 & 0.39 & 0.61 & 0.65 \\
\hline Canada & 1987Q1-2015Q4 & -0.47 & 0.54 & 0.74 & 0.76 \\
\hline Germany & 1960Q1-2016Q1 & -0.19 & 0.64 & 0.82 & 0.37 \\
\hline France & 1976Q1-2016Q1 & -0.20 & 0.33 & 0.71 & 0.75 \\
\hline Italy & 1968Q4-2016Q1 & -0.21 & 0.47 & 0.79 & 0.16 \\
\hline Japan & 1978Q1-2016Q1 & 0.17 & 0.39 & 0.65 & 0.58 \\
\hline Korea & 1980Q1-2016Q1 & -0.26 & 0.37 & 0.57 & 0.74 \\
\hline New Zealand & 1977Q3-2016Q1 & -0.25 & 0.28 & -0.09 & 0.57 \\
\hline United Kingdom & 1985Q1-2015Q1 & -0.26 & 0.56 & 0.60 & 0.66 \\
\hline
\end{tabular}




\section{Table 4}

\section{Summary Statistics: Gaps Estimated Using Real Time Data}

\begin{tabular}{|lllll} 
& $\begin{array}{l}\text { AR(1) Model } \\
\text { Output Gap }\end{array}$ & $\begin{array}{l}\text { UC-HP } \\
\text { Model } \\
\text { Output Gap }\end{array}$ & $\begin{array}{l}\text { Hamilton } \\
\text { Filter }\end{array}$ & $\begin{array}{l}\text { Model-Avg. } \\
\text { Output Gap }\end{array}$ \\
\cline { 2 - 5 } $\begin{array}{r}\text { Correlation } \\
\text { with Revised } \\
\text { Gap }\end{array}$ & 0.85 & 0.61 & 0.94 & $\mathbf{0 . 9 7}$ \\
SD Revision & 0.34 & 1.31 & 1.02 & $\mathbf{0 . 4 3}$ \\
SD Scaled & 0.63 & 1.02 & 0.49 & $\mathbf{0 . 4 2}$ \\
Revision & & & &
\end{tabular}

Note: Bold denotes the most positive correlation between the revised and the real-time estimate for each output gap, and the smallest value when comparing the standard deviations of the revisions. The scaled standard deviations were obtained by dividing by the standard deviation of the corresponding output gap. The sample period for calculation of revision statistics is 1970Q1-2016Q1. 

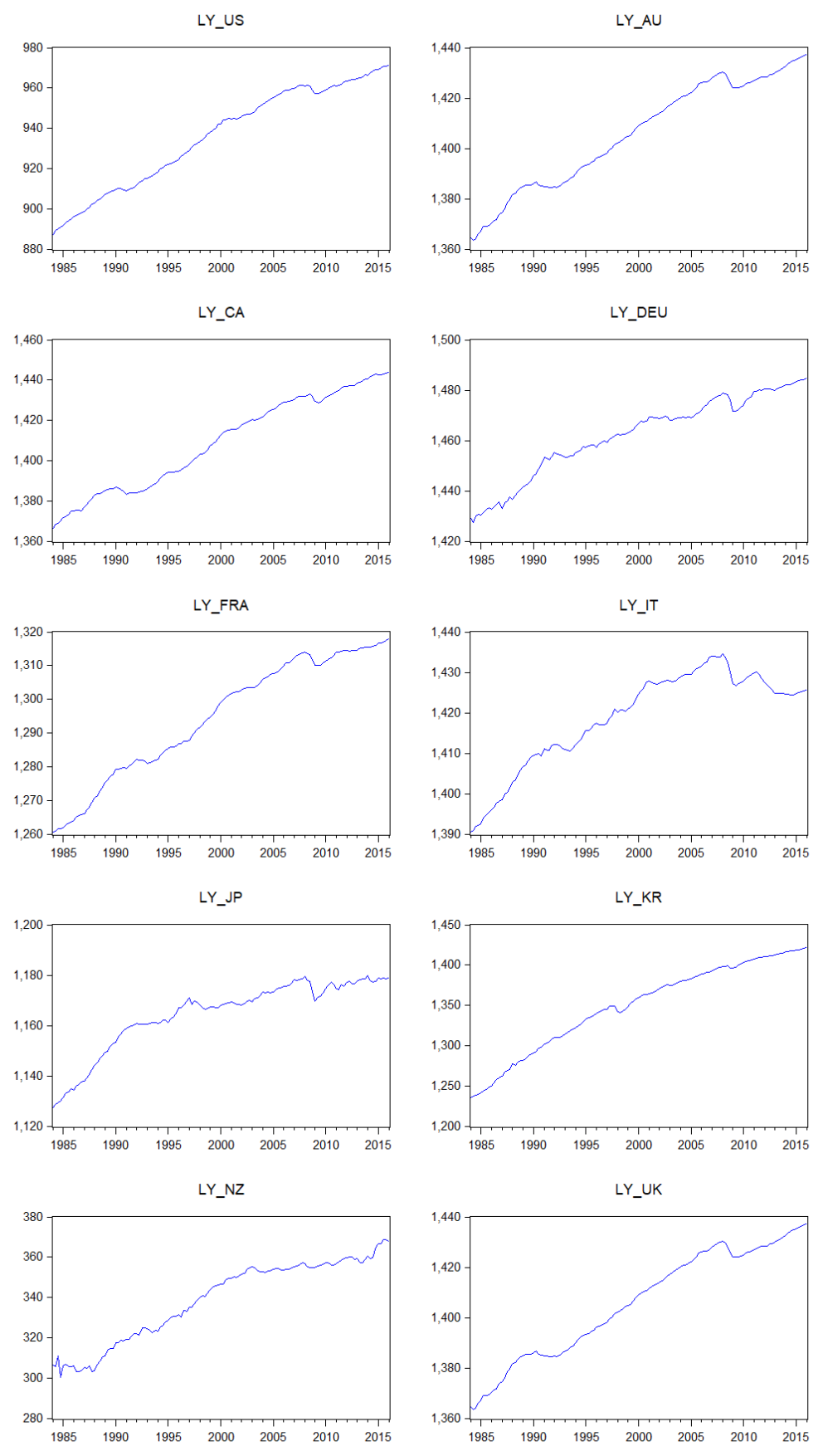

Fig. 1 - Log real GDP

Notes: From the top left and by row, the economies are US, Australia, Canada, Germany, France, Italy, Japan, Korea, New Zealand, and the United Kingdom. See Table 1 for details of the sample period for each economy. 

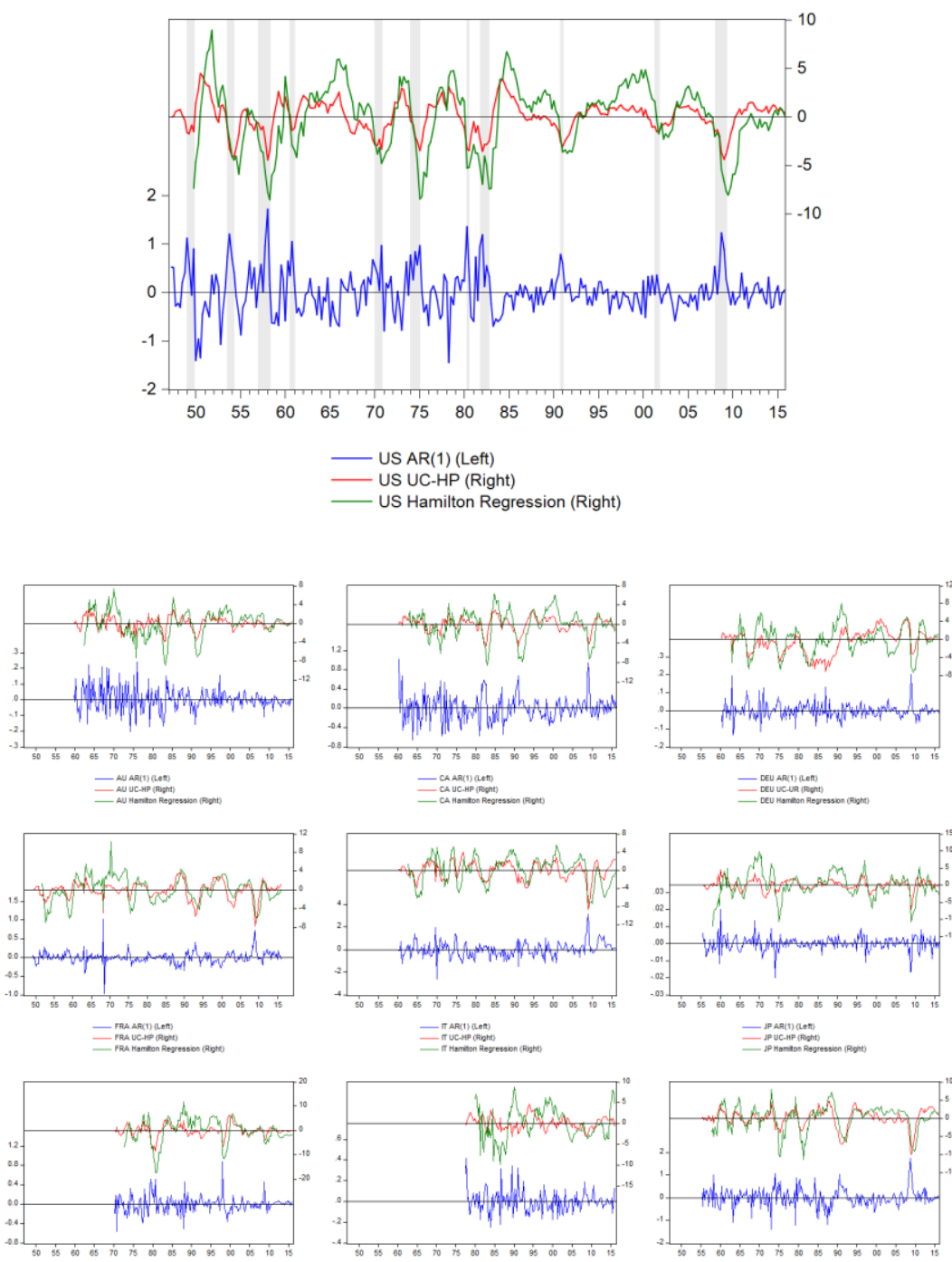

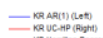
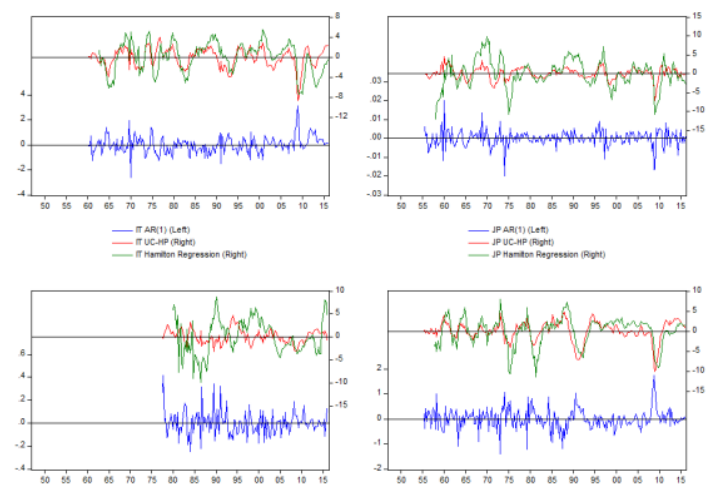

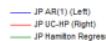

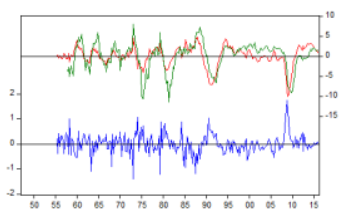

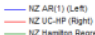

二 =

Fig. 2 - Output gaps based on competing models of real GDP

Note: The output gap for an AR(1) model is in blue (left axis), the output gap for a UC-HP model is in red (right axis), and the output gap obtained using Hamilton's regression approach is in green (right axis). Top row is the US (NBER recessions shaded) and then from second row left, the plots are for Australia, Canada, Germany, France, Italy, Japan, Korea, New Zealand, and the UK, respectively. The horizontal axis runs from 1947Q2-2016Q1. See Table 1 for details of the available sample period for each economy. 


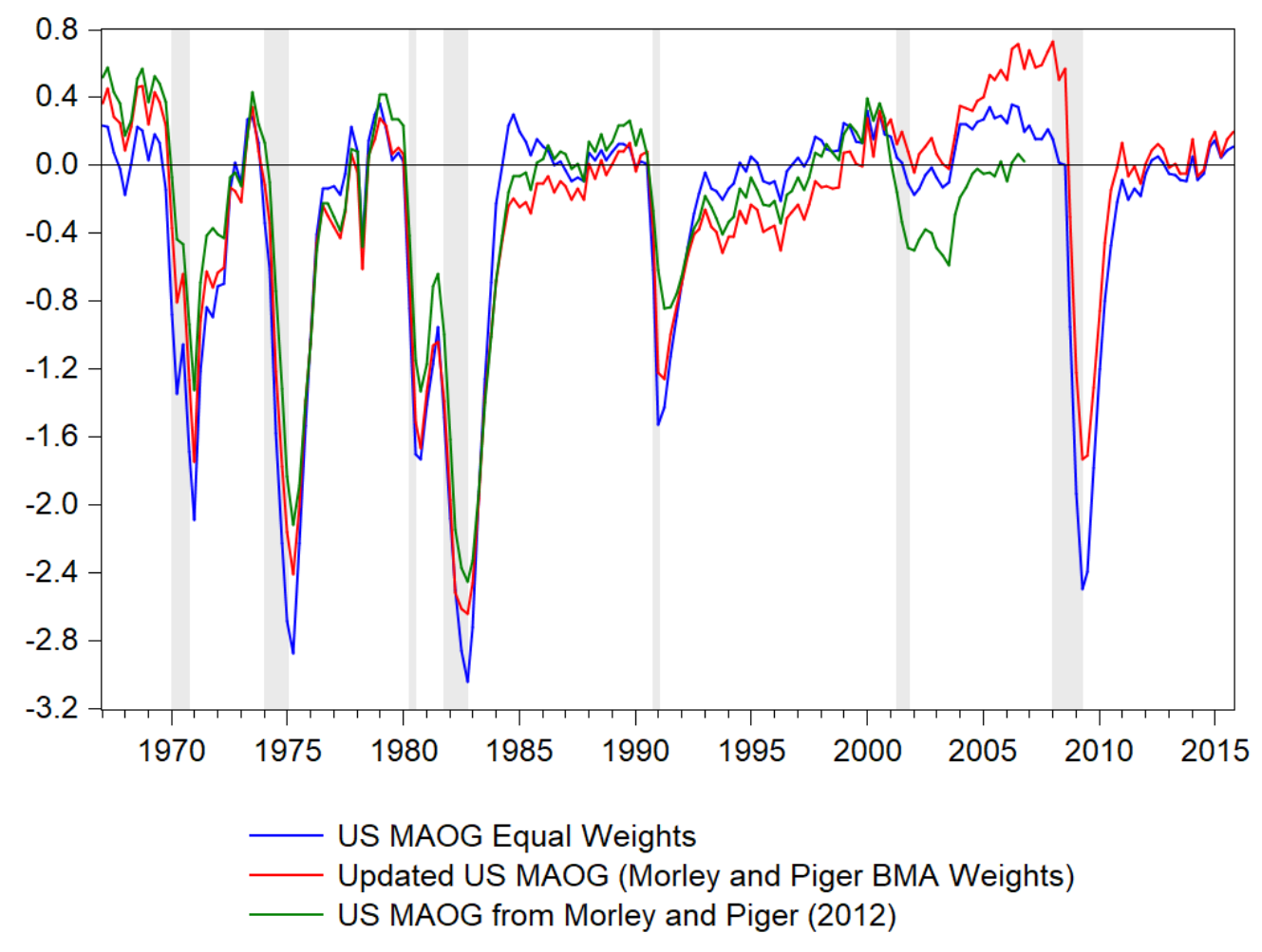

Fig. 3 - Model-averaged output gap for US real GDP for different weighting schemes, estimation methods, and sample periods (NBER recessions shaded)

Note: The model-averaged output gap for the 1947Q2-2016Q1 sample based on equal weights and Bayesian estimation is in blue, the model-averaged output gap for the 1947-2016Q1 sample based on BMA weights and MLE is red, and the model-averaged output gap for the vintage 1947Q2-2006Q4 sample from Morley and Piger (2012) based on BMA weights and MLE is in green. 


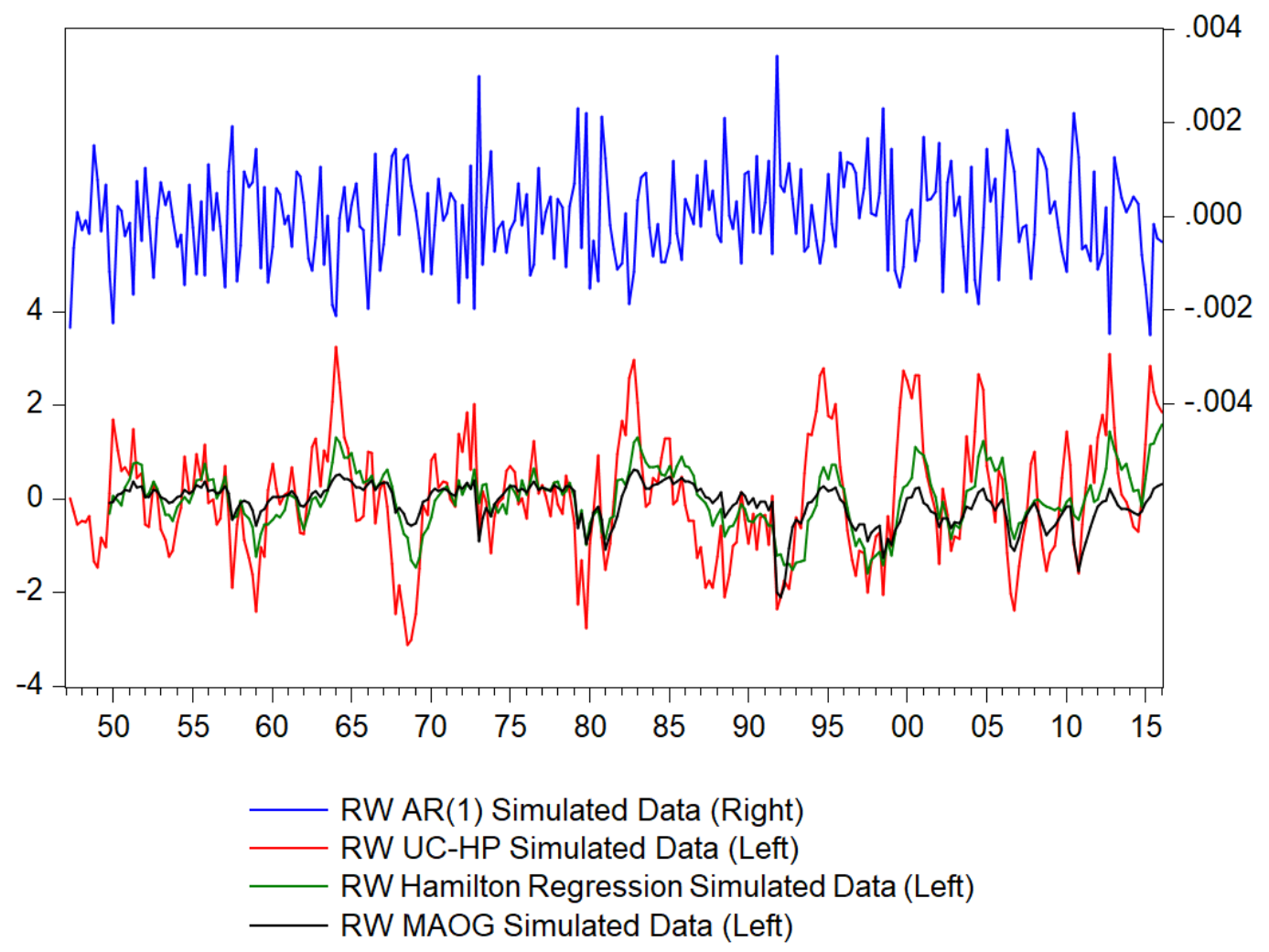

Fig. 4 - Model-averaged output gaps for a simulated random walk

Note: The model-averaged output gap for a simulated random walk of a sample length corresponding to the length of the observed sample for U.S. GDP is in black. The output gap for a UC-HP model for the same simulated random walk is in red, the output gap obtained using Hamilton's regression based approach is in green, and the output gap obtained using an AR(1) model is in blue (right axis). 


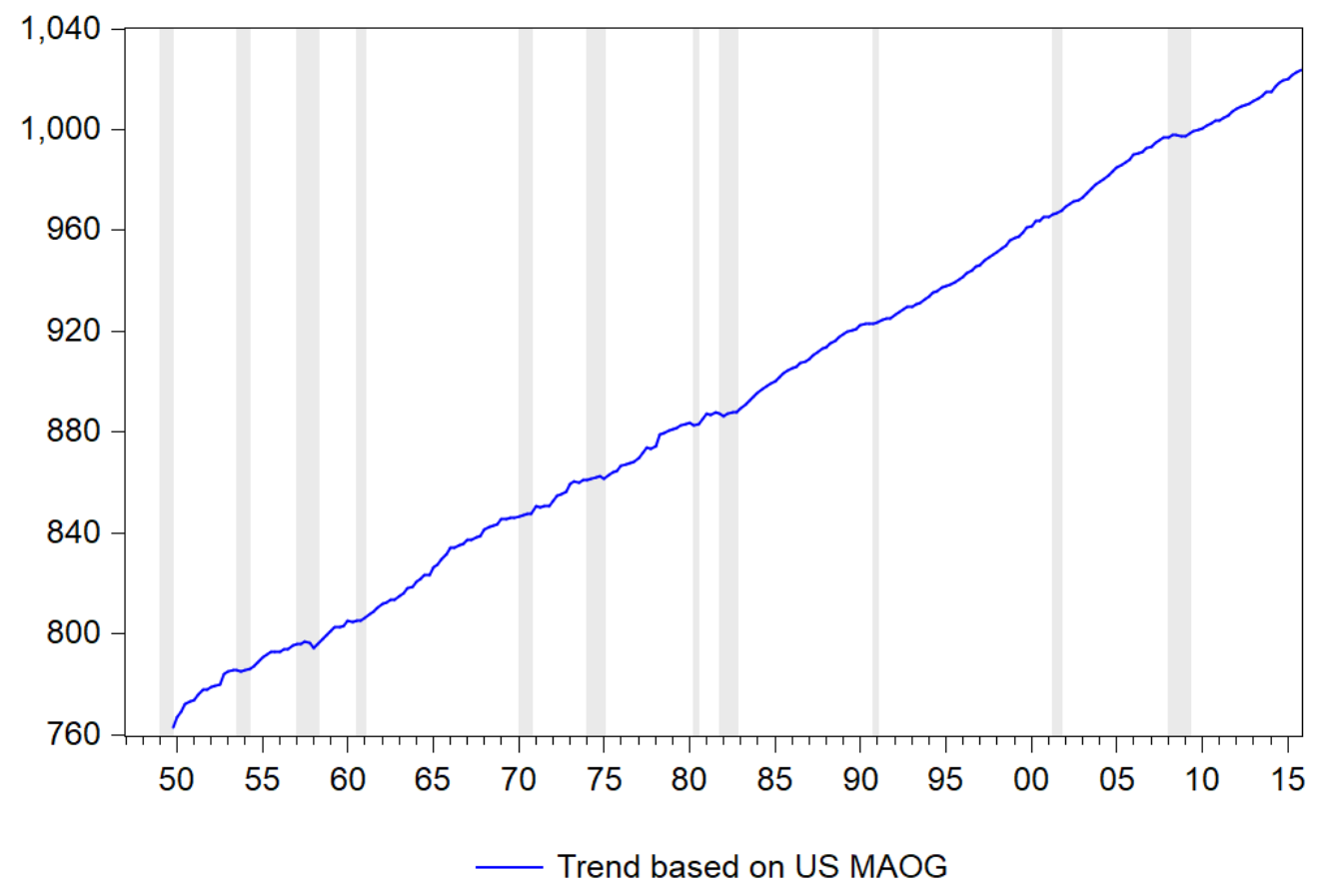

Fig. 5 - Estimated trend in US real GDP based on model-averaged output gap adjusted for breaks in mean (NBER recessions shaded)

Note: The trend estimate is calculated as the difference between 100 times log US real GDP and the US modelaveraged output gap for 1947Q2-2016Q1. 

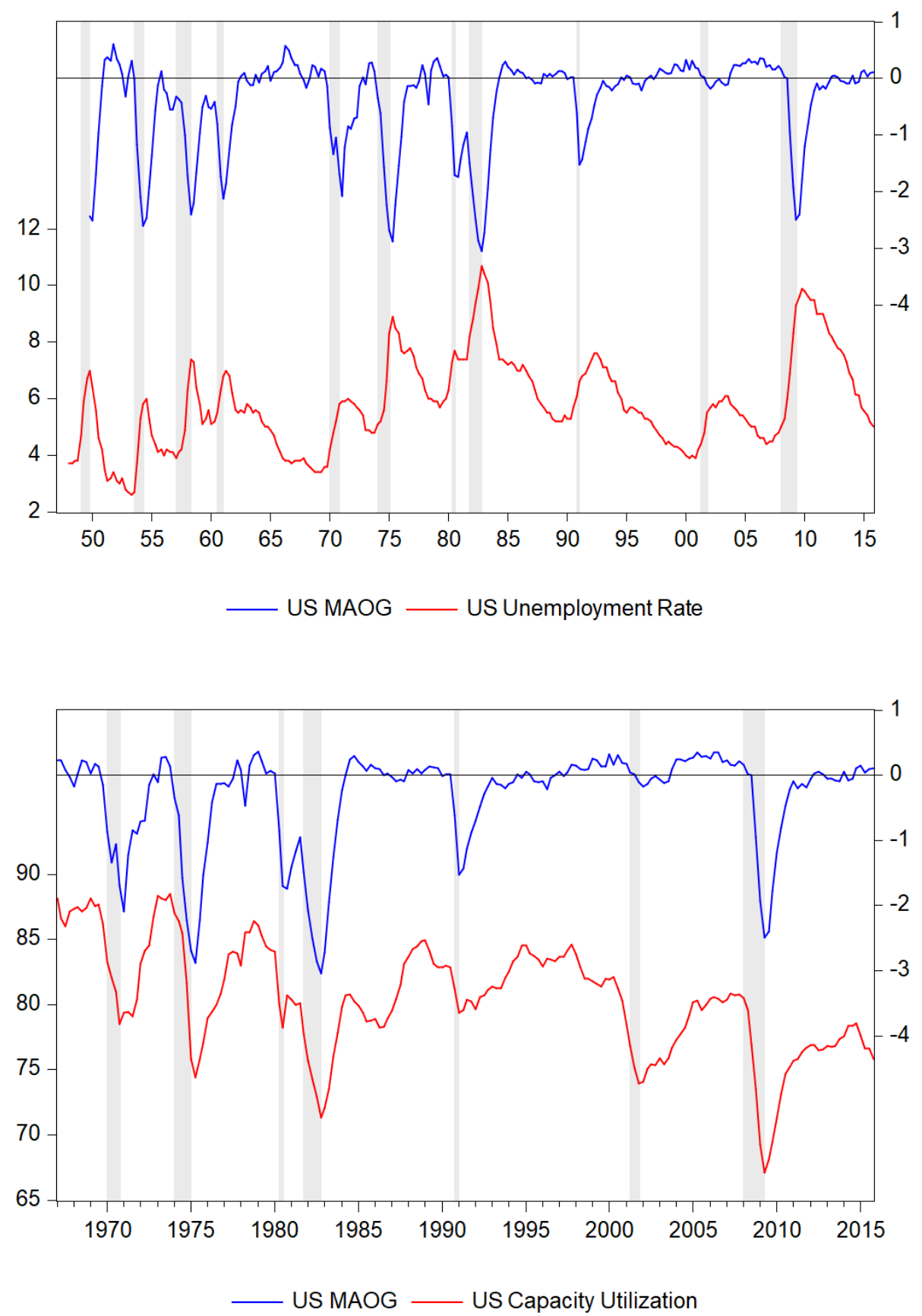

Fig. 6 - Model-averaged output gap for US real GDP and other measures of economic slack (NBER recessions shaded)

Notes: In the top panel, the model-averaged output gap for US real GDP for 1948Q1-2016Q1 is in blue and the unemployment rate for the corresponding sample period is in red. The model averaged gap is on the right axis, the unemployment rate is on the left axis. In the bottom panel, the model-averaged output gap for US real GDP for 1967Q1-2016Q1 is in blue and capacity utilization for the corresponding sample period is in red. The model averaged gap is on the right axis, the capacity utilization rate is on the left axis. 

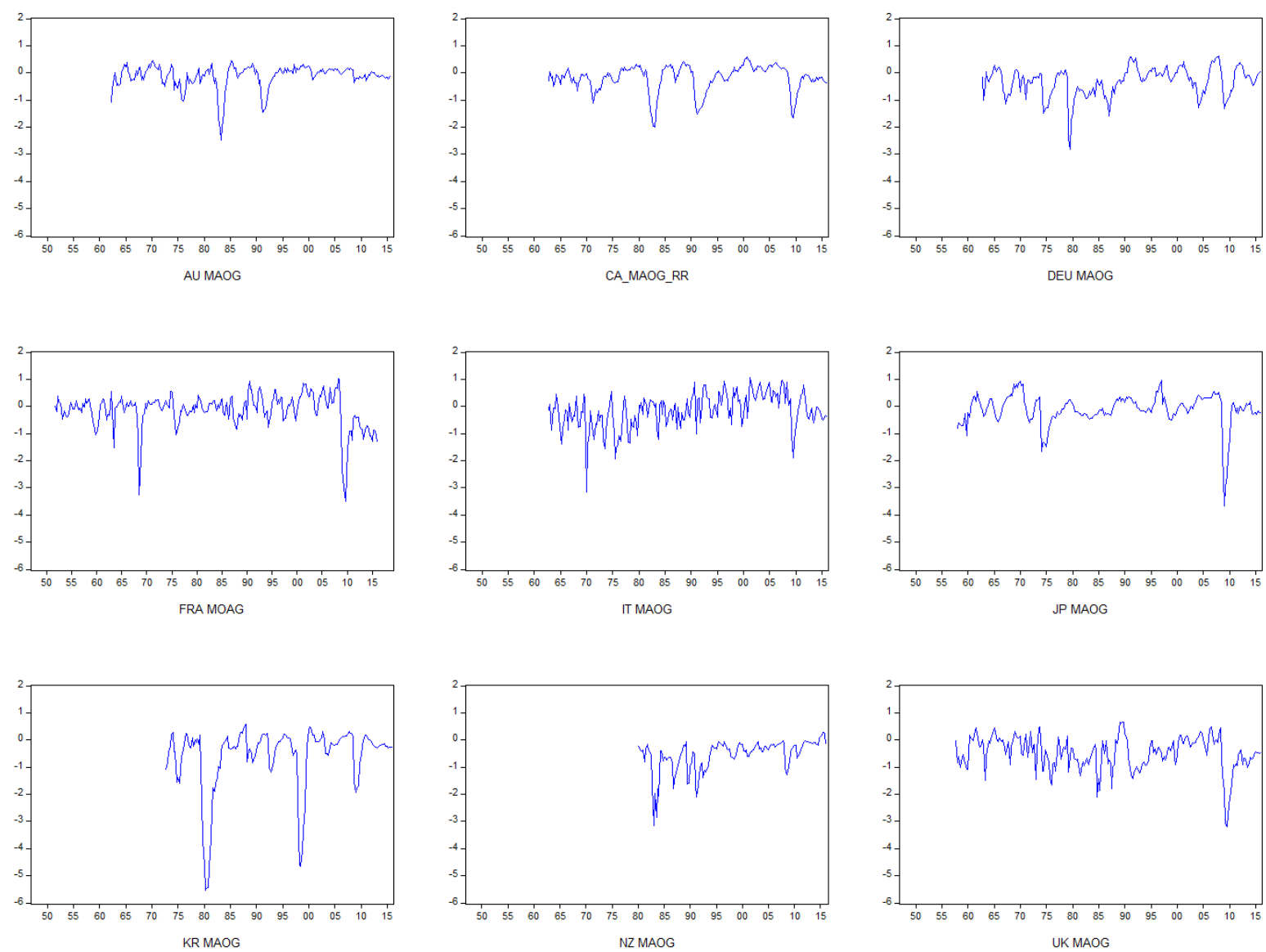

Fig. 7 - Model-averaged output gaps for real GDP from selected industrialized economies

Notes: From the top left and by row, the economies are Australia, Canada, Germany, France, Italy, Japan, Korea, New Zealand, and the United Kingdom. The horizontal axis runs from 1947Q2-2016Q1. See Table 1 for details of the available sample period for each economy. 

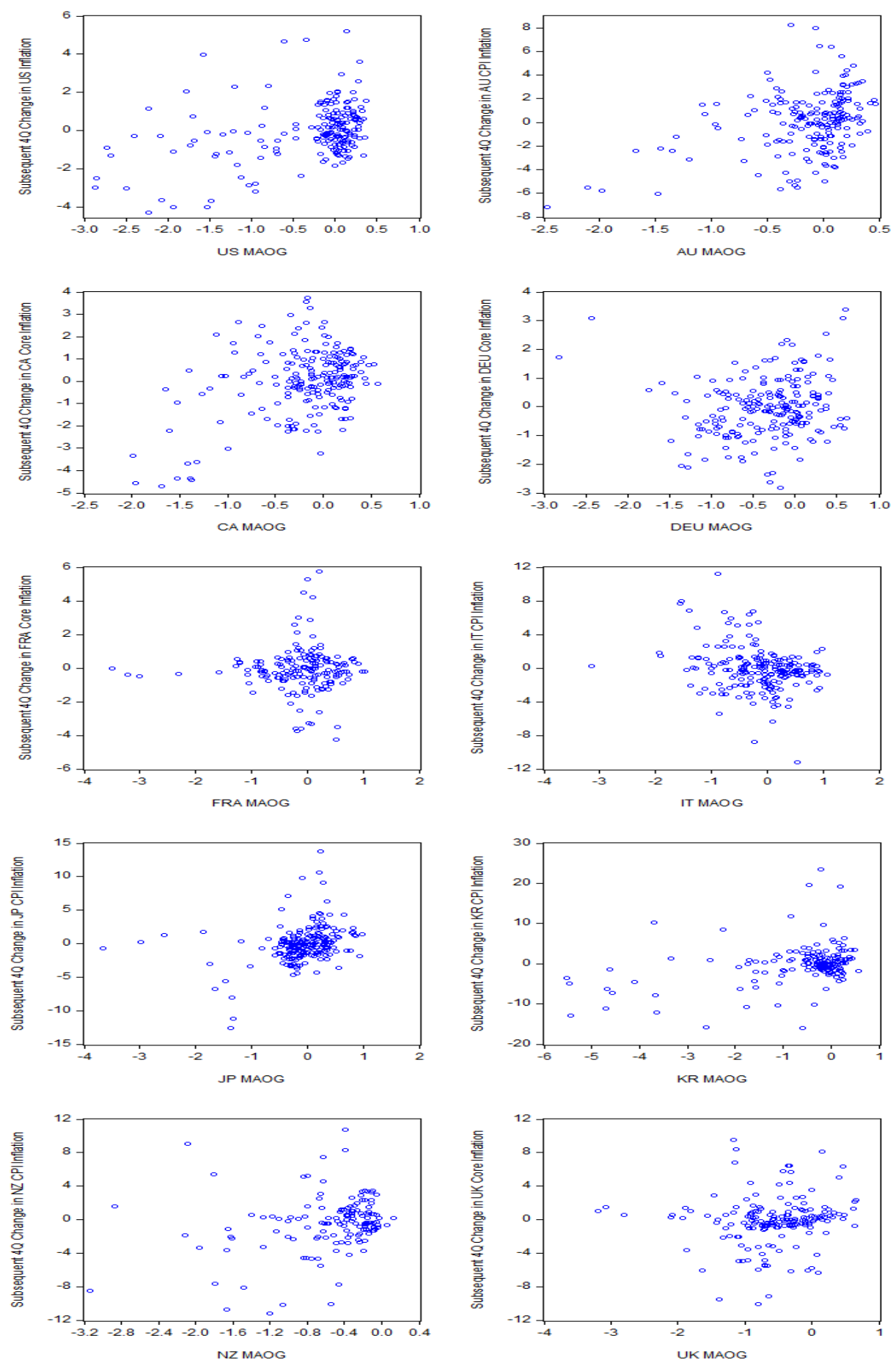

Fig. 8 - Phillips curves based on model-averaged output gaps

Note: Notes: From the top left and by row, the economies are US, Australia, Canada, Germany, France, Italy, Japan, Korea, New Zealand, and the United Kingdom. See Table 1 for details of the sample period for each economy. 

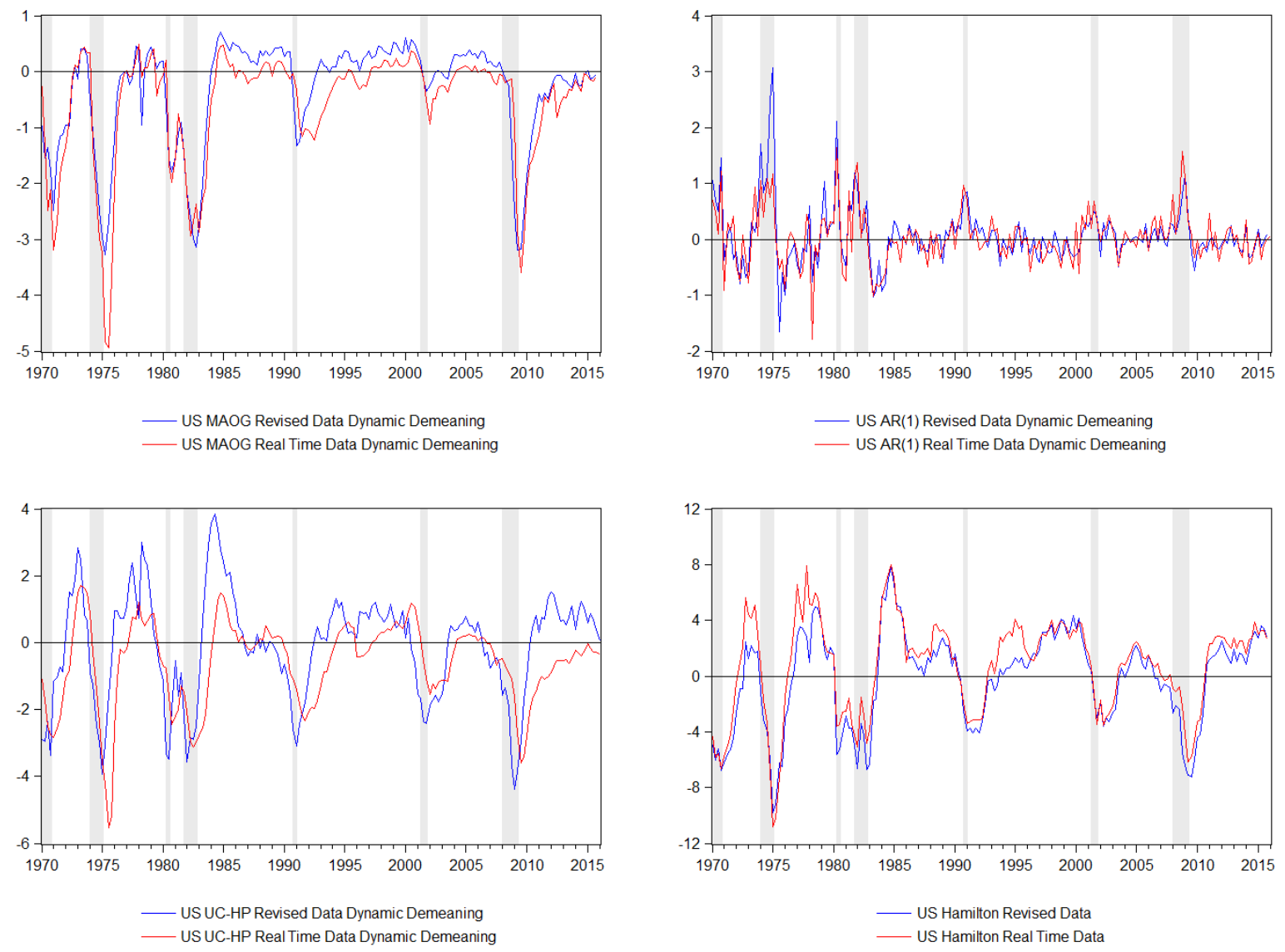

Fig. 9 - Model-averaged output gap for US real GDP with dynamic demeaning (NBER recessions shaded). Top left: Model Averaged Output Gap. Top Right: AR(1). Bottom left HP filter. Bottom right: Hamilton Gap. 


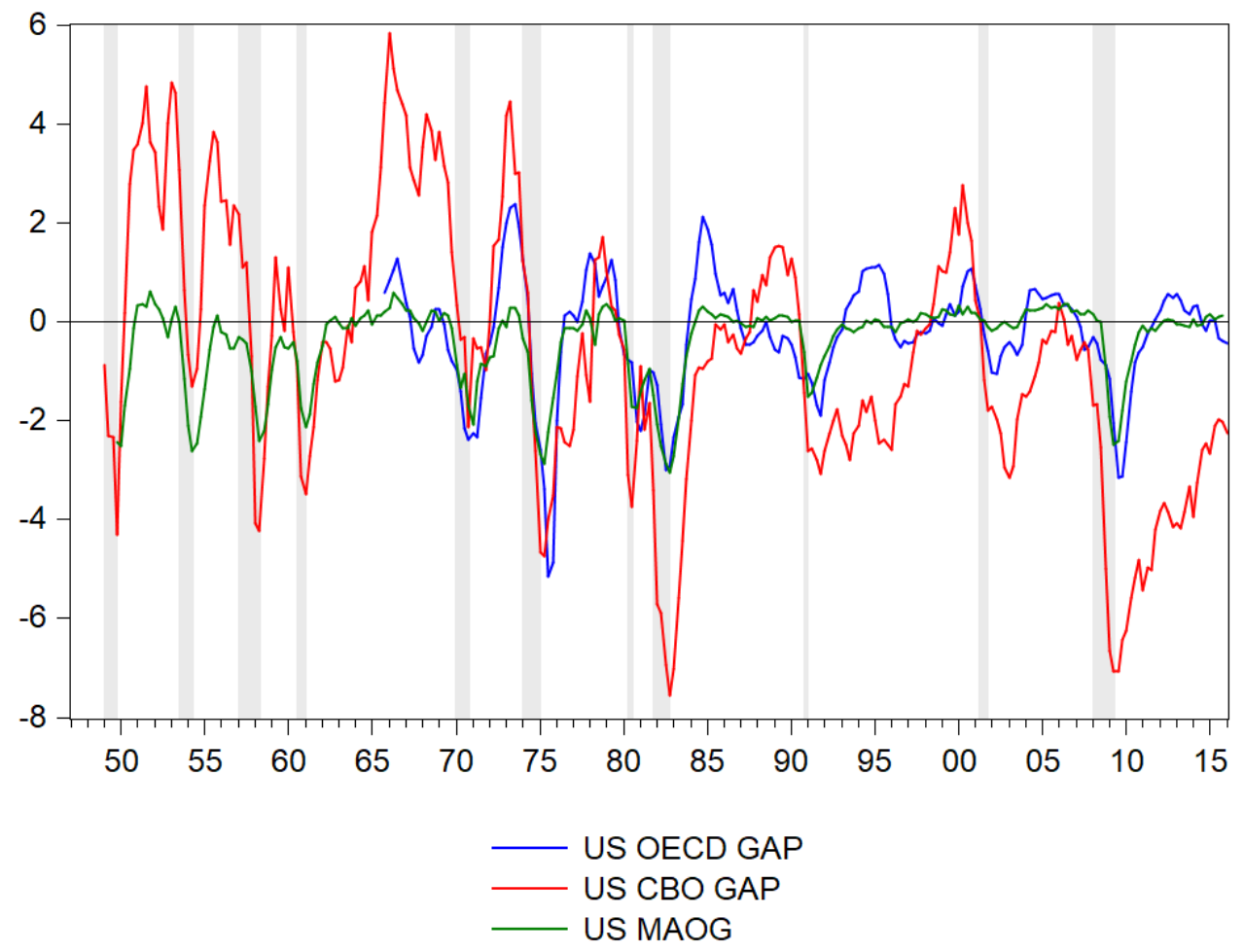

Fig. 10 - OECD estimate of the US output gap (Blue), CBO estimate of the output gap (Red), and model-averaged output gap for US real GDP with dynamic demeaning (Green). NBER recessions shaded. 


\section{Appendix}

\begin{tabular}{|c|c|c|c|c|}
\hline \multicolumn{5}{|c|}{$\begin{array}{c}\text { Table A.1 } \\
\text { Summary of Data and Data Sources }\end{array}$} \\
\hline Economy & $\begin{array}{l}\text { Gross Domestic } \\
\text { Product }\end{array}$ & Inflation & Unemployment & Capacity \\
\hline United States & $\begin{array}{l}\text { Quarterly, real, } \\
\text { SAGDPC1 FRED }\end{array}$ & $\begin{array}{l}\text { Quarterly, SA } \\
\text { JCXFE FRED }\end{array}$ & $\begin{array}{l}\text { Monthly, SA } \\
\text { UNRATE FRED }\end{array}$ & $\begin{array}{l}\text { Monthly, SA } \\
\text { TCU FRED }\end{array}$ \\
\hline $\mathrm{AU}$ & $\begin{array}{l}\text { Quarterly, real, SA } \\
\text { OECD LNBRQSA } \\
\text { (ABS) }\end{array}$ & $\begin{array}{l}\text { Quarterly, SA } \\
\text { OECD }\end{array}$ & $\begin{array}{l}\text { Monthly, SA } \\
\text { GLFSURSA, ABS }\end{array}$ & $\begin{array}{l}\text { Monthly, SA } \\
\text { National bank survey } \\
\text { NAB Data }\end{array}$ \\
\hline $\mathrm{CA}$ & $\begin{array}{l}\text { Quarterly, real SA } \\
\text { OECD VOBARSA }\end{array}$ & $\begin{array}{l}\text { CPI, CPI Core } \\
\text { Monthly (SA, NSA) } \\
\text { StatCan }\end{array}$ & $\begin{array}{l}\text { Monthly, SA } \\
\text { OECD MEI }\end{array}$ & $\begin{array}{l}\text { Quarterly, SA } \\
\text { StatCan (NAICS) } \\
\text { Series Code 029-002 }\end{array}$ \\
\hline DEU & $\begin{array}{l}\text { Quarterly, Real, SA } \\
\text { OECD LBRQRSA }\end{array}$ & $\begin{array}{l}\text { CPI, CPI Core } \\
\text { Monthly (SA, NSA) } \\
\text { OECD MEI }\end{array}$ & $\begin{array}{l}\text { Monthly, SA } \\
\text { OECD MEI }\end{array}$ & $\begin{array}{l}\text { Quarterly, SA } \\
\text { OECD MEI }\end{array}$ \\
\hline FRA & $\begin{array}{l}\text { Quarterly, real, SA } \\
\text { OECD LBRQRSA }\end{array}$ & $\begin{array}{l}\text { CPI, CPI Core } \\
\text { Monthly (SA, NSA) } \\
\text { OECD MEI }\end{array}$ & $\begin{array}{l}\text { Monthly, SA } \\
\text { OECD MEI }\end{array}$ & $\begin{array}{l}\text { Quarterly, SA } \\
\text { OECD MEI }\end{array}$ \\
\hline IT & $\begin{array}{l}\text { Quarterly, real, SA } \\
\text { OECD VOBARSA }\end{array}$ & $\begin{array}{l}\text { CPI, CPI Core } \\
\text { Monthly (SA, NSA) } \\
\text { OECD MEI }\end{array}$ & $\begin{array}{l}\text { Monthly, SA } \\
\text { OECD MEI }\end{array}$ & $\begin{array}{l}\text { Quarterly, SA } \\
\text { OECD MEI }\end{array}$ \\
\hline JP & $\begin{array}{l}\text { Quarterly, Real, } \\
\text { NSA } \\
\text { Cabinet Office }\end{array}$ & $\begin{array}{l}\text { CPI, CPI Core } \\
\text { Monthly, NSA } \\
\text { OECD MEI }\end{array}$ & $\begin{array}{l}\text { Monthly, SA } \\
\text { Cabinet Office }\end{array}$ & $\begin{array}{l}\text { Quarterly, SA } \\
\text { Japan Ministry of } \\
\text { Economy }\end{array}$ \\
\hline KR & $\begin{array}{l}\text { Quarterly, Real, SA } \\
\text { OECD VOBARSA }\end{array}$ & $\begin{array}{l}\text { CPI, CPI Core } \\
\text { (NSA, SA) } \\
\text { OECD MEI }\end{array}$ & $\begin{array}{l}\text { Monthly, SA } \\
\text { OECD MEI }\end{array}$ & $\begin{array}{l}\text { Quarterly, SA } \\
\text { KOSTAT }\end{array}$ \\
\hline $\mathrm{NZ}$ & $\begin{array}{l}\text { Quarterly, Real, SA } \\
\text { OECD VOBARSA }\end{array}$ & $\begin{array}{l}\text { CPI, CPI core } \\
\text { NSA, SA }\end{array}$ & $\begin{array}{l}\text { Monthly, SA } \\
\text { OECD MEI }\end{array}$ & $\begin{array}{l}\text { Quarterly, SA } \\
\text { OECD MEI }\end{array}$ \\
\hline UK & $\begin{array}{l}\text { Quarterly, Real, SA } \\
\text { OECD VOBARSA }\end{array}$ & $\begin{array}{l}\text { CPI, CPI Core, SA } \\
\text { OECD MEI }\end{array}$ & $\begin{array}{l}\text { Monthly, SA } \\
\text { OECD MEI }\end{array}$ & $\begin{array}{l}\text { Quarterly, SA } \\
\text { Office of National } \\
\text { Statistics (Business } \\
\text { Tendency Survey) }\end{array}$ \\
\hline
\end{tabular}

Notes: All monthly series were converted to quarterly frequency using arithmetic averages. The series that were not seasonally adjusted by the source were seasonally adjusted using the X12 filter. To facilitate comparison with previous studies, we had a preference for OECD VOBARSA GDP series, except when an alternative measure was available for a much longer sample. In all cases when we used a series other than the VOBARSA measure, the correlation with the VOBARSA measure for the overlapping sample periods was above 0.97 . Similarly, we had a preference for the OECD Main Economic Indicator (MEI) harmonized unemployment rate, except when an alternative measure was available for a much longer sample. In the case of the US, the FRED series match the preferred OECD measures. 


\begin{tabular}{|c|c|c|c|}
\hline \multicolumn{4}{|c|}{$\begin{array}{c}\text { Table A.2 } \\
\text { Structural Break Tests }\end{array}$} \\
\hline Economy & $\begin{array}{c}\text { Number of } \\
\text { breaks }\end{array}$ & \multicolumn{2}{|c|}{$\begin{array}{c}\text { Break Dates } \\
\text { (Test Statistics and significance } \\
\text { level) }\end{array}$} \\
\hline US & $1(2)$ & $\begin{array}{c}2000 \mathrm{Q} 3 \\
\left(19.10^{* * *}\right)\end{array}$ & $\begin{array}{c}1973 \mathrm{Q} 1 \\
(6.88) \\
p \text {-value }=0.13\end{array}$ \\
\hline Australia & 0 & \multicolumn{2}{|c|}{-} \\
\hline Canada & 1 & \multicolumn{2}{|c|}{$\begin{array}{c}1974 Q 2 \\
\left(20.278^{* * *}\right)\end{array}$} \\
\hline France & 1 & \multicolumn{2}{|c|}{$\begin{array}{c}1974 \mathrm{Q} 2 \\
(65.82 * * *)\end{array}$} \\
\hline Germany & $1(2)$ & $\begin{array}{c}1973 \mathrm{Q} 2 \\
(15.871 * * *)\end{array}$ & $\begin{array}{c}1991 \mathrm{Q} 2 \\
(4.95) \\
p \text {-value }=0.11\end{array}$ \\
\hline Italy & 1 & \multicolumn{2}{|c|}{$\begin{array}{c}1974 \mathrm{Q} 1 \\
(48.127 * * *)\end{array}$} \\
\hline Japan & 2 & $\begin{array}{c}\text { 1973Q2 } \\
\left(131.695^{* * *}\right)\end{array}$ & $\begin{array}{c}1991 \mathrm{Q} 3 \\
\left(19.87^{* * *}\right)\end{array}$ \\
\hline Korea & 1 & \multicolumn{2}{|c|}{$\begin{array}{c}\text { 1997Q3 } \\
(26.07 * * *) \\
\end{array}$} \\
\hline $\begin{array}{c}\text { New } \\
\text { Zealand }\end{array}$ & 0 & \multicolumn{2}{|c|}{-} \\
\hline UK & 0 (1) & \multicolumn{2}{|c|}{$\begin{array}{c}1973 \mathrm{Q} 1 \\
(6.07) \\
p \text {-value }=0.15\end{array}$} \\
\hline
\end{tabular}

Notes: The table reports the results of the Bai-Perron $(1998,2003)$ sequential test. We consider trimming of $15 \%$ of the sample from its end points and between breaks for admissible break dates. The table reports the number of breaks, the estimated break date, and the test statistic with the significance level (three stars corresponds to significance at the $1 \%$ level, two stars corresponds to significance at the 5\% level, and one star corresponds to significance at the $10 \%$ level). In the cases when the Bai-Perron test selected a smaller number of breaks than the number of breaks commonly imposed in the literature, we list the maximum number of breaks we considered in parentheses and the $p$-value for the additional break date below the test statistic. 


\begin{tabular}{|c|c|c|c|c|}
\hline \multicolumn{5}{|c|}{$\begin{array}{c}\text { Table A.3 } \\
\text { Tests for Markov Switching }\end{array}$} \\
\hline & & & Alternatives & \\
\hline \multirow[b]{2}{*}{ United States } & Null & L-shaped & U-shaped & Depth \\
\hline & $\operatorname{AR}(2)$ & $\begin{array}{c}0.151 \\
(0.409) \\
1.213\end{array}$ & $\begin{array}{c}2.516 \\
(0.166) \\
4.272\end{array}$ & $\begin{array}{c}8.401 \\
(0.055) \\
9.243\end{array}$ \\
\hline \multirow{3}{*}{ Australia } & $\operatorname{AR}(2)-t$ & $\begin{array}{c}0.307 \\
(0.164) \\
0.721\end{array}$ & $\begin{array}{c}1.373 \\
(0.161) \\
2.797\end{array}$ & $\begin{array}{c}9.554 \\
(0.035) \\
9.022\end{array}$ \\
\hline & $\mathrm{AR}(2)$ & $\begin{array}{c}0.880 \\
(0.116) \\
1.833\end{array}$ & $\begin{array}{c}0.197 \\
(0.688) \\
3.270\end{array}$ & $\begin{array}{c}14.826 \\
(0.005) \\
9.218\end{array}$ \\
\hline & $\operatorname{AR}(2)-\mathrm{t}$ & $\begin{array}{c}0.637 \\
(0.070) \\
0.904\end{array}$ & $\begin{array}{l}0.020 \\
0.999 \\
2.814\end{array}$ & $\begin{array}{c}10.686 \\
(0.045) \\
9.195\end{array}$ \\
\hline \multirow[t]{2}{*}{ Canada } & $\operatorname{AR}(2)$ & $\begin{array}{c}0.003 \\
(0.989) \\
0.932\end{array}$ & $\begin{array}{l}1.914 \\
0.221 \\
3.516\end{array}$ & $\begin{array}{l}24.122 \\
(0.000) \\
9.224\end{array}$ \\
\hline & $\operatorname{AR}(2)-t$ & $\begin{array}{c}0.003 \\
(0.689) \\
0.932\end{array}$ & $\begin{array}{c}1.914 \\
(0.221) \\
3.516\end{array}$ & $\begin{array}{l}17.825 \\
(0.000) \\
9.575\end{array}$ \\
\hline \multirow[t]{2}{*}{ Germany } & $\mathrm{AR}(2)$ & $\begin{array}{c}0.974 \\
(0.210) \\
1.109\end{array}$ & $\begin{array}{c}3.688 \\
(0.030) \\
3.376\end{array}$ & $\begin{array}{c}59.000 \\
(0.000) \\
8.846\end{array}$ \\
\hline & $\operatorname{AR}(2)-\mathrm{t}$ & $\begin{array}{c}0.030 \\
(0.437) \\
0.885\end{array}$ & $\begin{array}{l}6.250 \\
(0.000) \\
2.2886\end{array}$ & $\begin{array}{l}108.344 \\
(0.000) \\
10.756\end{array}$ \\
\hline \multirow[t]{2}{*}{ France } & $\mathrm{AR}(2)$ & $\begin{array}{c}0.001 \\
(1.000) \\
1.223\end{array}$ & $\begin{array}{c}1.220 \\
(0.432) \\
3.915\end{array}$ & $\begin{array}{l}2.803 \\
(0.825) \\
27.829\end{array}$ \\
\hline & $\operatorname{AR}(2)-\mathrm{t}$ & $\begin{array}{c}0.000 \\
(1.000) \\
1.507\end{array}$ & $\begin{array}{c}0.673 \\
(0.236) \\
2.458\end{array}$ & $\begin{array}{c}50.794 \\
(0.000) \\
9.826\end{array}$ \\
\hline \multirow[t]{2}{*}{ Italy } & $\mathrm{AR}(2)$ & $\begin{array}{c}1.962 \\
(0.035) \\
1.736\end{array}$ & $\begin{array}{c}1.065 \\
(0.452) \\
4.641\end{array}$ & $\begin{array}{c}1.827 \\
(0.800) \\
10.903\end{array}$ \\
\hline & $\operatorname{AR}(2)-\mathrm{t}$ & $\begin{array}{c}0.057 \\
(0.462) \\
1.356\end{array}$ & $\begin{array}{c}1.171 \\
(0.201) \\
2.255\end{array}$ & $\begin{array}{c}0.473 \\
(0.960) \\
10.732\end{array}$ \\
\hline \multirow[t]{2}{*}{ Japan } & $\mathrm{AR}(2)$ & $\begin{array}{c}0.492 \\
(0.146) \\
1.353\end{array}$ & $\begin{array}{c}2.752 \\
(0.121) \\
4.177\end{array}$ & $\begin{array}{l}36.310 \\
(0.081) \\
54.323\end{array}$ \\
\hline & $A R(2)-t$ & $\begin{array}{l}3.774 \\
0.000 \\
1.315\end{array}$ & $\begin{array}{c}2.527 \\
(0.040) \\
2.397\end{array}$ & $\begin{array}{l}15.378 \\
(0.011) \\
10.137\end{array}$ \\
\hline \multirow[t]{2}{*}{ Korea } & $\mathrm{AR}(2)$ & $\begin{array}{c}0.027 \\
(0.389) \\
1.172\end{array}$ & $\begin{array}{c}0.369 \\
(0.382) \\
2.251\end{array}$ & $\begin{array}{l}17.964 \\
(0.290) \\
27.062\end{array}$ \\
\hline & $\operatorname{AR}(2)-t$ & $\begin{array}{c}0.026 \\
(0.527) \\
1.449\end{array}$ & $\begin{array}{c}0.0940 \\
(0.537) \\
3.896\end{array}$ & $\begin{array}{c}2.079 \\
(0.825) \\
11.332\end{array}$ \\
\hline \multirow[t]{2}{*}{ New Zealand } & $\operatorname{AR}(2)$ & $\begin{array}{c}1.231 \\
(0.085) \\
1.458\end{array}$ & $\begin{array}{c}0.138 \\
(0.758) \\
4.036\end{array}$ & $\begin{array}{c}6.198 \\
(0.265) \\
11.115\end{array}$ \\
\hline & $\operatorname{AR}(2)-\mathrm{t}$ & $\begin{array}{c}1.235 \\
(0.030) \\
0.917\end{array}$ & $\begin{array}{c}0.206 \\
(0.462) \\
2.157\end{array}$ & $\begin{array}{c}2.974 \\
(0.570) \\
10.055\end{array}$ \\
\hline \multirow[t]{2}{*}{ United Kingdom } & $\operatorname{AR}(2)$ & $\begin{array}{c}0.001 \\
(1.000) \\
1.158\end{array}$ & $\begin{array}{c}2.969 \\
(0.075) \\
3.399\end{array}$ & $\begin{array}{c}16.000 \\
(0.002) \\
9.914\end{array}$ \\
\hline & $\operatorname{AR}(2)-\mathrm{t}$ & $\begin{array}{c}0.001 \\
(1.000) \\
0.993\end{array}$ & $\begin{array}{c}0.065 \\
(0.708) \\
2.440\end{array}$ & $\begin{array}{l}6.592 \\
(0.260) \\
11.464\end{array}$ \\
\hline
\end{tabular}

Notes: The test statistics for the L-shaped and U-shaped Recessions are based on Carrasco et al. (2014). The test statistics for the depth-based recovery alternatives are based on estimation using a grid for the continuous probabilities. All $p$-values (reported in parentheses) and 5\% critical values (reported below $p$-values) are based on parametric bootstrap experiments with 499 simulations. All tests accounted for structural breaks in the long-run growth rate. 


\begin{tabular}{|c|c|c|c|c|c|c|}
\hline \multicolumn{7}{|c|}{$\begin{array}{c}\text { Table A.4 } \\
\text { Unit Root and Stationarity Tests }\end{array}$} \\
\hline & & \multicolumn{5}{|c|}{ Test } \\
\hline & $\begin{array}{c}\text { Adjustment for structural } \\
\text { breaks }\end{array}$ & $\begin{array}{l}\mathrm{ADF} \\
\text { (asymptotic } p \text { - } \\
\text { value) }\end{array}$ & $\begin{array}{c}\text { DF } \\
\text { ERS* }\end{array}$ & $\begin{array}{c}\text { LMC } \\
\text { (bootstrapped } p- \\
\text { value) }\end{array}$ & $\begin{array}{c}\text { KPSS } \\
\text { (bootstrapped } p \text { - } \\
\text { value) }\end{array}$ & $\begin{array}{c}\text { MPS } \\
\text { (bootstrapped } p \\
\text { value) }\end{array}$ \\
\hline US & 1973Q1, 2000Q3 & $\begin{array}{l}-3.201 \\
(0.085)\end{array}$ & 8.903 & $\begin{array}{c}0.085 \\
(0.362)\end{array}$ & $\begin{array}{c}0.163 \\
(0.182)\end{array}$ & $\begin{array}{c}1.634 \\
(0.065)\end{array}$ \\
\hline $\mathrm{AU}$ & None & $\begin{array}{l}-1.834 \\
(0.363)\end{array}$ & 3.209 & $\begin{array}{c}2.088 \\
(0.330)\end{array}$ & $\begin{array}{c}0.211 \\
(0545) \\
\end{array}$ & $\begin{array}{l}10.876 \\
(0.015)\end{array}$ \\
\hline $\mathrm{CA}$ & 1974Q2 & $\begin{array}{l}-2.289 \\
(0.438) \\
\end{array}$ & 2.404 & $\begin{array}{c}3.411 \\
(0.010) \\
\end{array}$ & $\begin{array}{c}0.378 \\
(0.116)\end{array}$ & $\begin{array}{c}3.698 \\
(0.201) \\
\end{array}$ \\
\hline FRA & 1974Q2 & $\begin{array}{l}-1.585 \\
(0.796) \\
\end{array}$ & 2.575 & $\begin{array}{c}1.897 \\
(0.377) \\
\end{array}$ & $\begin{array}{c}0.186 \\
(0.683) \\
\end{array}$ & $\begin{array}{c}7.835 \\
(0.000)\end{array}$ \\
\hline DEU & 1973Q1, 1991Q2 & $\begin{array}{l}-2.696 \\
(0.239)\end{array}$ & 2.889 & $\begin{array}{c}2.564 \\
(0.025)\end{array}$ & $\begin{array}{c}0.274 \\
(0.055)\end{array}$ & $\begin{array}{l}12.440 \\
(0.000)\end{array}$ \\
\hline IT & 1974Q1 & $\begin{array}{c}0.525 \\
(0.993)\end{array}$ & 2.686 & $\begin{array}{c}1.502 \\
(0.151)\end{array}$ & $\begin{array}{c}0.318 \\
(0.729) \\
\end{array}$ & $\begin{array}{c}3.080 \\
(0.101)\end{array}$ \\
\hline JP & 1973Q1, 1991Q3 & $\begin{array}{l}-3.147 \\
(0.098)\end{array}$ & 2.461 & $\begin{array}{c}0.063 \\
(0.603)\end{array}$ & $\begin{array}{c}0.152 \\
(0.357)\end{array}$ & $\begin{array}{c}0.030 \\
(0.537)\end{array}$ \\
\hline KR & 1997Q3 & $\begin{array}{l}-3.055 \\
(0.120)\end{array}$ & 3.078 & $\begin{array}{c}0.071 \\
(0.839)\end{array}$ & $\begin{array}{c}0.574 \\
(0.386)\end{array}$ & $\begin{array}{c}0.430 \\
(0.307)\end{array}$ \\
\hline $\mathrm{NZ}$ & None & $\begin{array}{l}-2.618 \\
(0.273)\end{array}$ & 4.072 & $\begin{array}{l}1.573 \\
(0.261)\end{array}$ & $\begin{array}{c}0.182 \\
(0.407)\end{array}$ & $\begin{array}{c}6.432 \\
(0.100)\end{array}$ \\
\hline UK & 1973Q2 & $\begin{array}{l}-2.448 \\
(0.353)\end{array}$ & 2.981 & $\begin{array}{c}1.225 \\
(0.256)\end{array}$ & $\begin{array}{c}0.139 \\
(0.708)\end{array}$ & $\begin{array}{l}12.294 \\
(0.005)\end{array}$ \\
\hline
\end{tabular}

Notes: The 5\% asymptotic critical value for the DF-ERS unit root tests is -1.941 . We also performed unit root and stationarity tests that allowed for structural breaks in the variance and unit root tests that did not allow for structural breaks in the long-term drift. The results for the different specifications that allow for breaks in the variance and specifications that do not allow for structural breaks in means are available upon request. Allowing for structural breaks in the variance did not alter the $p$-values of any of the tests substantially. 


\begin{tabular}{|c|c|c|c|}
\hline \multicolumn{4}{|c|}{$\begin{array}{c}\text { Table A.5 } \\
\text { Prior Distributions for Model Parameters }\end{array}$} \\
\hline & Parameter Description & $\operatorname{Model}(\mathrm{s})$ & Prior \\
\hline$\mu$ & $\begin{array}{l}\text { Unconditional mean } \\
\text { growth }\end{array}$ & $\begin{array}{c}\text { All except } \\
\text { UC-HP and BB }\end{array}$ & $N\left(1,3^{2}\right)$ \\
\hline$\gamma_{0}$ & $\begin{array}{l}\text { Growth in expansion } \\
\text { regime }\end{array}$ & $\mathrm{BB}$ & $N\left(2.5,3^{2}\right)$ \\
\hline$-\gamma_{1}$ & Impact of other regime & $\mathrm{BB}$ & $\operatorname{Gamma}\left(\frac{15}{2}, \frac{5}{2}\right)$ \\
\hline$\lambda$ & Bounceback coefficient & $\mathrm{BB}$ & $N\left(0,0.25^{2}\right)$ \\
\hline$-\tau$ & $\begin{array}{l}\text { Mean of transitory shocks } \\
\text { in other regime }\end{array}$ & UC-FP & $\operatorname{Gamma}\left(\frac{15}{2}, \frac{5}{2}\right)$ \\
\hline$\phi_{j}$ & AR parameter at lag $j$ & $\begin{array}{l}\text { All except } \\
\text { UC-HP }\end{array}$ & $N\left(0,\left(\frac{0.25}{j}\right)^{2}\right)_{[|z|>1, \phi(z)=0]}$ \\
\hline$p_{00}$ & $\begin{array}{l}\text { Expansion regime } \\
\text { continuation probability }\end{array}$ & $\begin{array}{l}\text { BB, } \\
\text { UC-FP }\end{array}$ & $\operatorname{Beta}(1,20)$ \\
\hline$p_{11}$ & $\begin{array}{l}\text { Other regime continuation } \\
\text { probability }\end{array}$ & $\begin{array}{c}\mathrm{BB}, \\
\mathrm{UC}-\mathrm{FP}\end{array}$ & $\operatorname{Beta}(5,15)$ \\
\hline$v$ & $\begin{array}{l}\text { Degree of freedom for } \\
\text { Student } t \text { errors }\end{array}$ & $\begin{array}{l}\text { All except } \\
\text { UC }\end{array}$ & $\operatorname{Gamma}\left(\frac{1}{2}, \frac{0.1}{2}\right)$ \\
\hline$\frac{1}{\sigma_{e}}, \frac{1}{\sigma_{\eta}}, \frac{1}{\sigma_{\omega}}$ & $\begin{array}{l}\text { Precision for independent } \\
\text { shocks }\end{array}$ & $\begin{array}{c}\text { All except } \\
\text { UCUR and UCUR-FP }\end{array}$ & $\operatorname{Gamma}\left(\frac{5}{2}, \frac{2}{2}\right)$ \\
\hline$\Sigma_{\eta \omega}^{-1}$ & $\begin{array}{l}\text { Precision for correlated } \\
\text { shocks }\end{array}$ & UCUR and UCUR-FP & Wishart $\left(5,2 \times I_{2}\right)$ \\
\hline
\end{tabular}

